ANL/EAD/TM-19

W

Extent of Chromium Contamination beneath the 60s Pits in the Chemical Waste Landfill at Sandia National Laboratories, Albuquerque, New Mexico

by R. Johnson

Environmental Assessment Division,

Argonne National Laboratory, 9700 South Cass Avenue, Argonne, Illinois 60439

September 1994

.

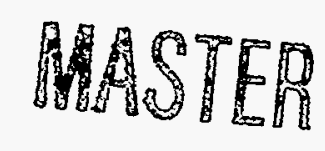

DISTRIBUTION OF THIS DOCUMENT IS UNLIMITED 
This report is printed on recycled paper. 


\section{DISCLAIMER}

This report was prepared as an account of work sponsored by an agency of the United States Government. Neither the United States Government nor any agency thereof, nor any of their employees, make any warranty, express or implied, or assumes any legal liability or responsibility for the accuracy, completeness, or usefulness of any information, apparatus, product, or process disclosed, or represents that its use would not infringe privately owned rights. Reference herein to any specific commercial product, process, or service by trade name, trademark, manufacturer, or otherwise does not necessarily constitute or imply its endorsement, recommendation, or favoring by the United States Government or any agency thereof. The views and opinions of authors expressed herein do not necessarily state or reflect those of the United States Government or any agency thereof. 


\section{DISCLAIMER}

Portions of this document may be illegible in electronic image products. Images are produced from the best available original document. 


\section{CONTENTS}

ENGLISH/METRIC AND METRIC/ENGLISH EQUIVALENTS $\ldots \ldots \ldots \ldots \ldots$

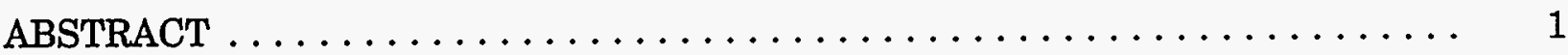

1 INTRODUCTION $\ldots \ldots \ldots \ldots \ldots \ldots \ldots \ldots \ldots \ldots \ldots \ldots \ldots \ldots \ldots \ldots$

2 CONTAMINATION EXTENT AT THE 60 s PITS $\ldots \ldots \ldots \ldots \ldots \ldots$

2.1 Available Data . . . . . . . . . . . . . . . . . . . . 3

2.2 Background Threshold Levels . . . . . . . . . . . . . . . . . 4

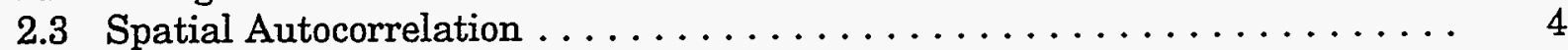

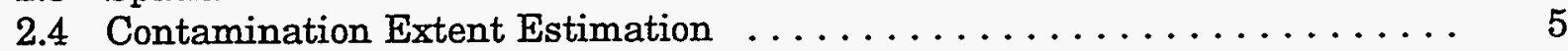

2.5 Additional Sampling Recommendations $\ldots \ldots \ldots \ldots \ldots \ldots \ldots$

3 APPLICATION OF AN ADAPTIVE SAMPLING PROGRAM APPROACH . . . . 7

3.1 Base Case Analysis . . . . . . . . . . . . . . . . . . . 8

3.2 Impact of Spatial Autocorrelation Range $\ldots \ldots \ldots \ldots \ldots \ldots \ldots \ldots$

3.3 Impact of Initial Soft Information . . . . . . . . . . . . . . . 10

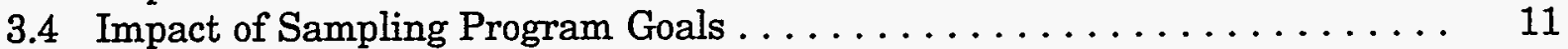

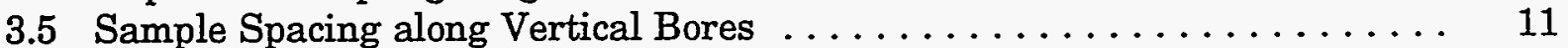

3.6 Comparison with Actual Sampling Program . . . . . . . . . . . . . 12

3.7 Contamination Identification vs. Delineation $\ldots \ldots \ldots \ldots \ldots \ldots \ldots$

4 CONCLUSIONS $\ldots \ldots \ldots \ldots \ldots \ldots \ldots \ldots \ldots \ldots \ldots \ldots \ldots \ldots \ldots \ldots$

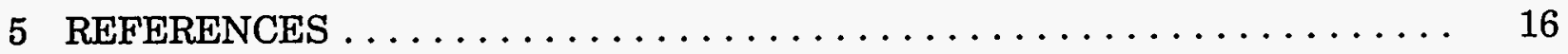

APPENDIX A: Sampling Results for the 60 s Pits $\ldots \ldots \ldots \ldots \ldots \ldots \ldots \ldots$

APPENDIX B: Illustrations $\ldots \ldots \ldots \ldots \ldots \ldots \ldots \ldots \ldots \ldots \ldots \ldots$

\section{FIGURES}

1 Chemical Waste Landfill . . . . . . . . . . . . . . . . . . . . 21

2 Location of 60 s Pits Bores with Chromium Data . . . . . . . . . . . 23

3 Chromium Results for Slant Bore Samples ................. 25

4 Covariance for Total Chromium Indicator Data from 60s Pits Samples . . . . . 27

5 Plan and Profile Views of 60s Pits Area Showing Location of Decision Points . . . . . . . . . . . . . . . . . . . 


\section{FIGURES (Cont.)}

6 Position of Vertical and Lateral Slices . . . . . . . . . . . . . . . . . 31

7 Lateral Distribution of Contamination Probability $\ldots \ldots \ldots \ldots \ldots \ldots$

8 Vertical Distribution of Contamination Probability .............. 35

9 Best Vertical Bore Locations for Defining the Vertical Extent

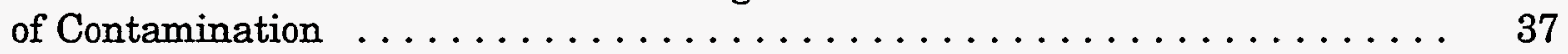

10 Impact Surface for New Vertical Bores $\ldots \ldots \ldots \ldots \ldots \ldots \ldots \ldots \ldots \ldots$

11 Base Case Sampling Program with Lateral Contamination Extent

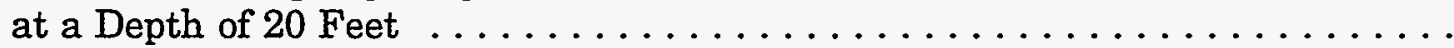

12 Base Case Sampling Program Expected Impact, Actual Impact, and Soil Classification . . . . . . . . . . . . . . . . . . . . . 43

13 Sampling Program Progress with Altered Spatial Autocorrelation Range and Lateral Contamination Extent at a Depth of 20 Feet ..........

14 Sampling Program Expected Impact, Actual Impact, and Soil Classification for 45-Foot Spatial Autocorrelation Range ...............

15 Sampling Program Progress with Altered Initial Location Assumptions

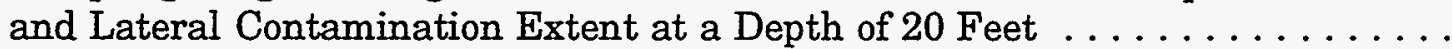

16 Sampling Program Expected Impact, Actual Impact, and Soil Classification for Altered Initial Location Assumptions

17 Sampling Program Progress with Altered Program Objectives and Lateral Contamination Extent at a Depth of 20 Feet ..............

18 Sampling Program Expected Impact, Actual Impact, and Soil

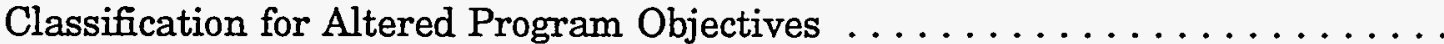

19 Information Gained versus Sample Spacing for the Base Adaptive Sampling Program Case and for the Case with Extended Spatial Autocorrelation Range . . . . . . . . . . . . . . . . . . . . . . . . . .

20 Sampling Program Progress for Contaminant Delineation and Lateral Contamination Extent at a Depth of 20 Feet ...............

21 Sampling Program Expected Impact, Actual Impact, and Soil

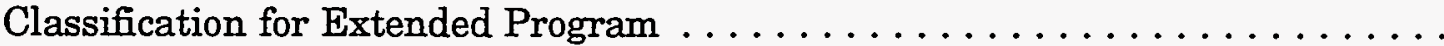

22 Percent Soil Volume Classified for Remediation at 80\% Certainty Level for Various Stages in the Sampling Program 


\section{ENGLISH/METRIC AND METRIC/ENGLISH EQUIVALENTS}

\begin{tabular}{|c|c|c|}
\hline Multiply & By & To Obtain \\
\hline \multicolumn{3}{|l|}{ English/Metric Equivalents } \\
\hline $\begin{array}{l}\text { acres } \\
\text { cubic feet }\left(\mathrm{ft}^{3}\right) \\
\text { cubic yards }\left(\mathrm{yd}^{3}\right) \\
\text { degrees Fahrenheit }\left({ }^{\circ} \mathrm{F}\right)-32 \\
\text { feet (ft) } \\
\text { gallons (gal) } \\
\text { gallons (gal) } \\
\text { inches (in.) } \\
\text { miles (mi) } \\
\text { pounds (lb) } \\
\text { short tons (tons) } \\
\text { short tons (tons) } \\
\text { square feet }\left(\mathrm{ft}^{2}\right) \\
\text { square yards }\left(\mathrm{yd}^{2}\right) \\
\text { square miles }\left(\mathrm{mi}^{2}\right) \\
\text { yards (yd) }\end{array}$ & $\begin{array}{l}0.4047 \\
0.02832 \\
0.7646 \\
0.5555 \\
0.3048 \\
3.785 \\
0.003785 \\
2.540 \\
1.609 \\
0.4536 \\
907.2 \\
0.9072 \\
0.09290 \\
0.8361 \\
2.590 \\
0.9144\end{array}$ & $\begin{array}{l}\text { hectares (ha) } \\
\text { cubic meters }\left(\mathrm{m}^{3}\right) \\
\text { cubic meters }\left(\mathrm{m}^{3}\right) \\
\text { degrees Celsius }\left({ }^{\circ} \mathrm{C}\right) \\
\text { meters }(\mathrm{m}) \\
\text { liters }(\mathrm{L}) \\
\text { cubic meters }\left(\mathrm{m}^{3}\right) \\
\text { centimeters }(\mathrm{cm}) \\
\text { kilometers }(\mathrm{km}) \\
\text { kilograms }(\mathrm{kg}) \\
\text { kilograms }(\mathrm{kg}) \\
\text { metric tons }(\mathrm{t}) \\
\text { square meters }\left(\mathrm{m}^{2}\right) \\
\text { square meters }\left(\mathrm{m}^{2}\right) \\
\text { square kilometers }\left(\mathrm{km}^{2}\right) \\
\text { meters }(\mathrm{m})\end{array}$ \\
\hline \multicolumn{3}{|l|}{ Metric/English Equivalents } \\
\hline $\begin{array}{l}\text { centimeters }(\mathrm{cm}) \\
\text { cubic meters }\left(\mathrm{m}^{3}\right) \\
\text { cubic meters }\left(\mathrm{m}^{3}\right) \\
\text { cubic meters }\left(\mathrm{m}^{3}\right) \\
\text { degrees Celsius }\left({ }^{\circ} \mathrm{C}\right)+17.78 \\
\text { hectares }(\mathrm{ha}) \\
\text { kilograms }(\mathrm{kg}) \\
\text { kilograms }(\mathrm{kg}) \\
\text { kilometers }(\mathrm{km}) \\
\text { liters }(\mathrm{L}) \\
\text { meters }(\mathrm{m}) \\
\text { meters }(\mathrm{m}) \\
\text { metric tons. }(\mathrm{t}) \\
\text { square kilometers }\left(\mathrm{km}^{2}\right) \\
\text { square meters }\left(\mathrm{m}^{2}\right) \\
\text { square meters }\left(\mathrm{m}^{2}\right)\end{array}$ & $\begin{array}{l}0.3937 \\
35.31 \\
1.308 \\
264.2 \\
1.8 \\
2.471 \\
2.205 \\
0.001102 \\
0.6214 \\
0.2642 \\
3.281 \\
1.094 \\
1.102 \\
0.3861 \\
10.76 \\
1.196\end{array}$ & $\begin{array}{l}\text { inches (in.) } \\
\text { cubic feet }\left(\mathrm{ft}^{3}\right) \\
\text { cubic yards }\left(\mathrm{yd}^{3}\right) \\
\text { gallons (gal) } \\
\text { degrees Fahrenheit }\left({ }^{\circ} \mathrm{F}\right) \\
\text { acres } \\
\text { pounds (lb) } \\
\text { short tons (tons) } \\
\text { miles (mi) } \\
\text { gallons (gal) } \\
\text { feet (ft) } \\
\text { yards (yd) } \\
\text { short tons (tons) } \\
\text { square miles }\left(\mathrm{mi}^{2}\right) \\
\text { square feet }\left(\mathrm{ft}^{2}\right) \\
\text { square yards }\left(\mathrm{yd}^{2}\right)\end{array}$ \\
\hline
\end{tabular}




\title{
EXTENT OF CHROMIUM CONTAMINATION BENEATH THE 60s PITS IN THE CHEMICAL WASTE LANDFILL AT SANDIA NATIONAL LABORATORIES, ALBUQUERQUE, NEW MEXICO
}

by

\author{
R. Johnson
}

\begin{abstract}
Plume $^{\mathrm{TM}}$ and SitePlanner ${ }^{\mathrm{TM}}$ were used to analyze the extent of chromium contamination beneath the 60s pits in the Chemical Waste Landfill at Sandia National Laboratories. On the basis of Plume ${ }^{\text {TM'S }}$ analysis with currently available sampling data, recommendations were made regarding the need for additional sampling and the proper locations for that sampling. Finally, a retrospective study was conducted for the site that evaluated the potential for cost savings if the characterization effort had followed an adaptive sampling program approach. Included in this retrospective study was an analysis of the impacts that spatial autocorrelation, soft information, and alternative sampling program goals have on sampling program progress. The conclusion is that by relying on an adaptive sampling program approach at the 60 s pits, and leveraging the little soft information that is available for this location, a significant gain in information could have been realized for the same number of bores.
\end{abstract}

\section{INTRODUCTION}

Past decision support for the adaptive sampling program at the Mixed Waste Landfill Integrated Demonstration (MWLID) at Sandia National Laboratories, Albuquerque, New Mexico, has provided evidence that an adaptive sampling program approach to site characterization can result in significant cost savings in three areas (Johnson 1993a). First, the cost per sample is reduced by emphasizing field screening results rather than relying on traditional off-site laboratory analyses. Second, by leveraging the real-time data generation capabilities of field screening techniques, adaptive sampling programs can be modified in the field to reflect the information being collected. This focuses sampling on those areas where data need to be collected, ultimately reducing the total number of bores that need to be drilled and samples that need to be taken and analyzed. Finally, by incorporating the appropriate stopping criteria, adaptive sampling programs can identify when the needs of the sampling program have been met, so data collection can cease. This ability allows the needs of the characterization program to be satisfied with one data collection effort, eliminating the overhead associated with repeated sampling programs. 
As part of the MWLID, two technologies have been developed and demonstrated for supporting adaptive sampling programs, SitePlanner ${ }^{\mathrm{TM}}$ and Plume ${ }^{\mathrm{TM}}$. The role of SitePlanner ${ }^{\mathrm{TM}}$ is qualitative support: data integration, management, and display. The role of Plume $\mathrm{T}^{\mathrm{TM}}$ is quantitative: fusing hard and soft information regarding contaminant location, estimating contaminant extent, measuring the uncertainty associated with those estimates, estimating the expected value to be obtained from additional samples, and assisting in identifying the locations for those samples so that maximum benefit is realized (Johnson 1993a). In fiscal year 1992 and 1993, these two technologies were applied to the unlined chromic acid pit in the Chemical Waste Landfill at Sandia National Laboratories, to assist in estimating the extent of subsurface chromium contamination and to suggest locations for additional bores. In fiscal year 1993 and 1994, focus moved to suspected chromium contamination beneath the 60 s pits in the landfill.

The objectives of the 60s pits work from a technology development/demonstration perspective were to (1) demonstrate an adaptive sampling program in the field by using SitePlanner ${ }^{\mathrm{TM}}$ and Plume $\mathrm{T}^{\mathrm{TM}}$; (2) investigate the impacts that various levels of initial soft information about contaminant location would have on the development and progress of adaptive sampling programs; and (3) evaluate the sensitivity of the analysis to estimates of the spatial autocorrelation present for the contaminant of concern and to the sampling program goals.

Because of logistical problems and the demands of other technologies being demonstrated at the 60 s pits, the first objective was abandoned. Consequently, Section 2 of this report evaluates the extent of chromium contamination beneath the 60 s pits on the basis of data collected by the Sandia environmental restoration program and during the course of sonic drilling by the MWLID. Additional sampling recommendations are given in Section 2.5. Section 3 of this report presents a retrospective study of the site. The purpose of this study was to determine the potential for cost savings if an adaptive sampling program had been used at the site from the start. As part of this analysis, special attention was given to the second and third objectives for the 60 s pits analysis.

This work was funded by the MWLID. Graphics were generated from SitePlanner ${ }^{\mathrm{TM}}$ and IslandGraphics ${ }^{\mathrm{TM}}$. Contamination estimation and sampling program design were done with Plume ${ }^{\mathrm{TM}}$. Supporting variogram analyses were handled with Geostatistical Software Library (GSLIB) utilities (Deutsch and Journel 1992). 


\section{CONTAMINATION EXTENT AT THE 60s PITS}

\subsection{AVAILABLE DATA}

The focus of analysis was the 60s pit area in the Chemical Waste Landfill (CWL) at Sandia National Laboratories. Figure $1^{*}$ shows the approximate locations of the two 60 s pits within the CWL. The locations of the north and south pits were based on engineering drawings for the site, which are probably more related to intent than actual fact. Little historic evidence exists that would indicate whether the pits in this vicinity were actually used for the disposal of chromic acid plating solution. No surficial evidence currently exists for the presence of the north and south pits in the 60s pits area of the CWL.

Some past sampling has taken place in the vicinity of the 60s pits. In 1985, IT Corporation completed a series of bores and trenches in and around the CWL. Seven of these bores were within the vicinity of the 60 s pits: T5, T6, T7, T9, T10, T12, and PE (Figure 2). At six of these bores, three samples were taken at depths of 15, 25 and $35 \mathrm{ft}$ and analyzed for metals, including chromium. Two soil samples were analyzed for chromium at the seventh bore. The results of these analyses are presented in Appendix A. At that time, IT concluded that there was no evidence of chromium contamination above background for these 20 samples (see Section 2.2 for discussion of background level).

In 1992 and 1993, the Sandia environmental restoration program completed a suite of bores in the vicinity of the CWL. Soil samples taken from these bores were analyzed for metals, including total chromium for a subset of the samples. Two of these bores, CWL $(170,225)$ and CWL(235,231), are located in the 60s pits area (Figure 2). Chromium was detected in 14 samples from these two bores (see Appendix A), at depths ranging from 10 to $200 \mathrm{ft}$. None of these samples had chromium values significantly above the background level.

In the summer of 1993, the MWLID used sonic drilling techniques to bore two slant holes from outside the CWL underneath the general vicinity of the 60s pit area, S60P and N60P (Figure 2). These two bores were approximately $145 \mathrm{ft}$ in length and attained a depth of approximately $40 \mathrm{ft}$ at their westernmost tips. Thirty-two samples were collected at regular intervals along their length. These samples were analyzed for chromium with several different analytical techniques, including X-Ray Fluorescence (XRF) and Adsorptive Stripping Voltammetry (ASV), both of which can provide near real-time results. Unlike previous characterization work, both of these bores encountered chromium levels significantly higher than background (Appendix A). Figure 3 shows the distribution of chromium found along the length of these bores, both in plan and profile views.

\footnotetext{
* All figures are placed in Appendix B of this document.
} 


\subsection{BACKGROUND THRESHOLD LEVELS}

Plume $^{\mathrm{TM}}$ provides the ability to estimate contaminant extent based on an initial conceptual image of contaminant location and subsequent sampling results. The analysis used by Plume ${ }^{\mathrm{TM}}$ relies in part on indicator spatial statistics. A more complete description of Plume ${ }^{\mathrm{TM}}$ 's methodology can be found in Johnson (1993b). To use indicator spatial statistics for the data collected presumes that one has a threshold level that can be used to classify samples as either contaminated or clean, depending on contamination levels. The threshold level defined for this analysis is any chromium value significantly above background levels. The analysis is complicated by the fact that chromium analyses were conducted at different times by different labs using different analytical techniques. In general, any chromium value above $16 \mathrm{ppm}$ was considered significantly greater than background and indicative of chromium contamination.

The 20 samples collected by IT Corporation in 1985 ranged in total chromium from 4.7 to $15 \mathrm{ppm}$, with an average of $7.8 \mathrm{ppm}$. For this analysis, the IT samples were categorized as not having total chromium values significantly higher than the background level - a conclusion consistent with IT's own interpretation of their sampling data.

The 14 samples collected by the Sandia environmental restoration program included total chromium levels ranging from 2.4 to $6.7 \mathrm{ppm}$, with an average of $4.0 \mathrm{ppm}$. Total chromium values tended to increase with increasing depth, which is consistent with findings at background bores near the unlined chromic acid pit. These low levels of total chromium showed no evidence of significant contamination above background. Consequently, all 14 samples were categorized as not having total chromium values significantly higher than the background level.

Laboratory analysis of 31 of the 32 samples collected by the MWLI during slant hole boring showed the presence of chromium in all 31 samples, ranging from 4.9 to $4,800 \mathrm{ppm}$ total chromium. The range of low-end or background values for the MWLID samples was much closer to the results of the IT study than the Sandia study. Using the 16-ppm threshold for the background level, 14 samples were classified as contaminated; the remaining 18 samples had total chromium values significantly below the background level. The one remaining sample without laboratory results for chromium did have XRF and ASV values that were clearly below background for this sample.

\subsection{SPATIAL AUTOCORRELATION}

The analysis employed by Plume ${ }^{\mathrm{TM}}$ to estimate contaminated volumes depends on knowledge of the spatial autocorrelation present in the 60s pits area. A total of 66 samples collected in the 60 s pits area gave analytical results for chromium - 20 from the IT study, 14 from the Sandia study, and 32 from the MWLID study. GSLIB routines (Deutsch and Journel 1992) were used to estimate the indicator spatial autocorrelation range for chromium contamination in this area. On the basis of the data for the 66 samples and with the 
assumption of an isotropic spatial autocorrelation structure, the indicator spatial autocorrelation range fell between 30 and $40 \mathrm{ft}$ (Figure 4). A simple rule of thumb for contaminated areas is that the range of the indicator spatial autocorrelation is approximately equal to the average expected width of the contaminated area. The available 60s pits data were consistent with the indicator autocorrelation range estimated with GSLIB (Deutsch and Journel 1992). The best guess for an indicator spatial autocorrelation structure for this site was exponential, with a range of $35 \mathrm{ft}$.

\subsection{CONTAMINATION EXTENT ESTIMATION}

The extent of contamination for the 60 s pits area was estimated with Plume ${ }^{\mathrm{TM}}$. A complete description of Plume ${ }^{\mathrm{TM}}$ 's methodology can be found in Johnson (1993b). Plume ${ }^{\mathrm{TM}}$ requires a grid of "decision points" for the area under consideration. For the 60s pits area, a three-dimensional grid was used that included 5,000 decision points: 25 in the east-west direction, 25 in the north-south direction, and 8 vertical. Each decision point was separated by $8 \mathrm{ft}$. Figure 5 shows the location of decision points laterally relative to the location of soil bores and vertically relative to the trajectory of the slant bores. The decision points defined a volume of soil equal to $94,800 \mathrm{yd}^{3}$. Initially, Plume ${ }^{\mathrm{TM}}$ requires that each decision point be assigned a probability of contamination that reflects the best judgment of the technical staff involved. Because no historical evidence is available that chromium was disposed of at the site (although the possibility certainly exists), an initial probability of contamination equal to 0.33 was assigned to each decision point ( $\alpha=0.25, \beta=0.5$ for the underlying prior beta distributions at each decision point).

This base scenario was next updated with Plume ${ }^{\mathrm{TM}}$ and data for the 66 samples by using the indicator spatial autocorrelation function identified in Section 2.3. On the basis of these data, the initial assumed spatial distribution of contamination, and the assumed indicator spatial autocorrelation function, the estimated soil volume contaminated with chromium above background is approximately $5.8 \%$ of the total volume of soil, or approximately $5,500 \mathrm{yd}^{3}$ of soil. If a certainty level of $80 \%$ is required, the amount of soil classified as contaminated would be $0.2 \%$, or approximately $200 \mathrm{yd}^{3}$; the amount classified as clean would be $21.9 \%$, or $20,800 \mathrm{yd}^{3}$; and the amount categorized as uncertain would be $77.9 \%$, or $73,800 \mathrm{yd}^{3}$. As suggested by the large volume of soil classified as uncertain at the $80 \%$ level, a relatively large amount of uncertainty is associated with these estimates at the $80 \%$ level, which could be reduced by further sampling. A unit of soil classified as uncertain at the $80 \%$ level has a probability of contamination that lies somewhere between 0.2 and 0.8 .

Again, if one assumes a spatial autocorrelation range of $35 \mathrm{ft}$, the best guess for depth of contamination is approximately $60 \mathrm{ft}$ and for lateral extent is approximately $4,000 \mathrm{ft}^{2}$. Figure 6 shows the location of the vertical and lateral slices used to study the depth and extent of contamination. Figures 7 and 8 show the extent of chromium contamination in these lateral and vertical slices on the basis of the results for the 66 samples. The probability of contamination is coded from white (zero probability of contamination being present) to black (probability of contamination being present equal to one), and regions with probability of contamination greater than 0.5 are demarcated with 
heavy black lines. As is clear from Figures 7 and 8, the preponderance of uncertainty (i.e., grey areas) lies northeast of the directionally drilled bores where no hard sampling data exists, as well as immediately beneath the sections of directionally drilled bores that penetrated contamination.

\subsection{ADDITIONAL SAMPLING RECOMMENDATIONS}

A program to install more vertical bores at this site to assist in defining the depth of contamination and/or the total volume contaminated would need information regarding where the bores should be placed, how deep they should be, how many samples should be taken from them, and how much additional information could be obtained from more samples. If one is concerned about the total depth of contamination, then the best area in which to place a vertical bore is shown in Figure 9, with the area outlined in black. If one can use field screening techniques such as XRF and ASV to analyze samples while the boring is being done, then the total depth of the bore or bores installed can be determined on the basis of the field screening results. With a spatial autocorrelation range of $35 \mathrm{ft}$, a sample spacing of approximately $6 \mathrm{ft}$ would be more than adequate for delineating the bottom of the plume. If one had to preplan the total drilling depth (i.e., field screening of samples was not practical), then a depth of $65 \mathrm{ft}$ would be best, although the addition of a safety margin might be prudent. Given the data available for the 60 s pits and the fact that a much larger plume beneath the unlined chromic acid pit did not penetrate much below $70 \mathrm{ft}$, an 80 -ft total boring depth should be more than sufficient.

The main uncertainty associated with the volume of contaminated soil results from the lack of information north and northeast of the slant bores installed by the MWLID. Neither IT nor Sandia placed bores in this region earlier. Figure 10 provides a color-coded surface that shows the impact on the volume of soil classified as uncertain for different new vertical bore locations. The surface shows the impact of new bores, assuming these to be completed to a depth of $70 \mathrm{ft}$, with yellow indicating high information returns and black low returns. As one would expect, the best places to drill new bores are north and northeast of the main body of contamination because, where uncertainty is measured as the number of decision points with probability of contamination greater than 0.2 but less than 0.8 , these are the areas with the most uncertainty associated with the classification of decision points. One would expect significant gains in information (i.e., reduction in the number of decision points whose state is uncertain) from additional bores. Again, if field screening techniques could be used to provide results while drilling was under way, then completion depths and the location of subsequent bores could be directed on the basis of results as they were generated.

Figure 10 also illustrates the need for graphics that allow technical staff to see the results of their analyses. Note that Plume ${ }^{\mathrm{TM}}$ identifies an area southwest of the $60 \mathrm{~s}$ pits as a likely candidate for new vertical bores, partly because of the lack of bores in this area of the decision point grid. However, bores T9, T10, and CWL $(170,225)$ were all clean, so it is highly unlikely that there would be contamination in this area resulting from disposal in the 60 s pits. In this case, SitePlanner ${ }^{\mathrm{TM}}$ could be used to check the Plume ${ }^{\mathrm{TM}}$ results. 


\section{APPLICATION OF AN ADAPTIVE SAMPLING PROGRAM APPROACH}

Adaptive sampling programs rely on field screening technologies such as XRF and ASV to provide analytical results quickly enough to have an impact on the course of a sampling program. The availability of these technologies presents the possibility for using such an approach for delineating chromium contamination at the 60 s pits. This in turn means that sampling can focus on those areas where additional data provide the most value, rather than forcing the sampling program to adhere to a preplanned sampling grid. The ultimate advantage is a reduction in sampling program cost (cheaper analyses and fewer samples to analyze), superior results (sampling locations are selected to maximize the information obtained), and a removal of "surprises" once the program is complete (i.e., results returning from the laboratory that were unexpected and that require the site to be revisited). The latter is particularly important for minimizing the cost and time associated with characterizing a site because sampling program planning and mobilization costs can be significant.

The question at the 60s pits is what benefit would have been realized if an adaptive sampling program approach had been used at the site. This section presents a retrospective study of the 60 s pits that attempts to answer that question, focusing on the total number of borings and samples that an adaptive sampling program would have required to delineate chromium contamination at the 60s pits. This section further explores the impact that different assumptions about the spatial autocorrelation range, initial location of contamination, and sampling program objectives would have had on the course of an adaptive sampling program. For the retrospective analyses, it was assumed that the volume of soil delineated by the $50 \%$ level certainty with available sampling data was in fact the correct extent of contamination. This assumption was used to evaluate the results of Plume ${ }^{\mathrm{TM}} \mathrm{s}$ recommendations for sampling locations. The adaptive sampling programs are based on the assumption that no hard data are available upon which to base a sampling program design.

As a basis for comparison, a base-case adaptive sampling program was developed. The base case assumed that no contamination was disposed of in this area and assigned an initial beta probability density function at each decision point, with $\alpha=0.25$ and $\beta=0.5$, resulting in an initial contamination probability of 0.33 at each decision point. An exponential function with a range of $35 \mathrm{ft}$ was assumed for the indicator spatial autocorrelation present at the site. Finally, the objective of the sampling program was to minimize the uncertainty associated with volumetric classification of soils at the $80 \%$ certainty level.

For a site such as the 60s pits where there may be no initial hard sampling results, deducing the correct indicator spatial autocorrelation function to be used by $\mathrm{Plume}^{\mathrm{TM}}$ in its analyses is guesswork. As a sampling program progresses, the indicator spatial autocorrelation function can be refined to reflect sampling results. The initial indicator spatial autocorrelation assumptions can have a dramatic impact on the early course of the sampling program. To evaluate the impact of assumptions about the indicator spatial autocorrelation 
on adaptive sampling program progress at the 60s pits, a second adaptive sampling program was developed that is identical to the base case, except that the indicator spatial autocorrelation function was assumed to be exponential, with a range of $45 \mathrm{ft}$.

If few hard data are available to begin with, the initial course of a sampling program is largely driven by any available soft information, e.g., nonintrusive survey results, signs of stressed vegetation, or contaminant release locations. In the case of the $60 \mathrm{~s}$ pits, no records exist of contaminants being disposed of, nor is there any surficial evidence of where the pits might have been located. The only soft information available is engineering drawings of where the pits were supposed to have been installed and suggestions that chromic acid plating solution may have been disposed of in waste pits in the CWL other than the unlined and lined chromic acid pits.

To evaluate the impact of such soft information on the course of an adaptive sampling program, a third adaptive sampling program was developed. This third adaptive sampling program recognizes that some information (probably flawed) existed regarding the possible location of the 60 s pits and that, if contamination were present, its location should be related to the pits. The initial probability density functions used in this situation depended on the location of the respective decision point relative to the engineered drawing of the pits. Beta distribution values ranged from values of $\alpha=0.15$ and $\beta=0.5$ (contamination probability of 0.23 ) for decision points far away from the pits to values of $\alpha=0.3$ and $\beta=0.5$ (contamination probability of 0.38 ) for decision points immediately below the pits. As with the base case, the spatial autocorrelation was assumed to be exponential, with a range of $35 \mathrm{ft}$, and the objective of the sampling program was to minimize the uncertainty associated with volumetric estimates of contamination at the $80 \%$ level.

The objective function selected for a sampling program can also have a dramatic impact on the course of sampling. To illustrate this fact, a final adaptive sampling program was developed which assumed that the objective of the characterization was to minimize the volume of soils classified as uncertain at the 70\% level. Except for differences in the objective function, this program was identical to the base case. For each of these scenarios, Plume ${ }^{\mathrm{TM}}$ searched for new vertical bores that would extend down to $70 \mathrm{ft}$. To keep the analysis as simple as possible, Plume ${ }^{\mathrm{TM}}$ assumed that these bores would be sampled every $5 \mathrm{ft}$, a typical EPA requirement for soil bores.

\subsection{BASE CASE ANALYSIS}

Figure 11 shows the course the sampling program would have taken in the base case and the lateral extent of contamination at a depth of $20 \mathrm{ft}$ for selected program steps. The lateral area defined by the decision point grid is grey-shaded to represent the probability of contamination at a depth of $20 \mathrm{ft}$. The shading runs from white (no contamination present) to black (contamination known to exist). Eleven soil bores are ultimately installed, with only one encountering contamination. These eleven bores taken together reduce the volume of soils classified as uncertain at the $80 \%$ level from $100 \%$ at the outset of the sampling 
program to $33.4 \%$ after the completion of the eleventh bore. This provides an average impact of $6 \%$ uncertainty reduction per bore.

Figure 11 again highlights the need for a qualitative understanding of the analysis that SitePlanner ${ }^{\mathrm{TM}}$ provides for Plume ${ }^{\mathrm{TM}}$. After the eleventh bore, Plume ${ }^{\mathrm{TM}}$ still identifies a significant portion of the soil volume as uncertain at the $80 \%$ level. Figure 11 shows that some of this volume is located in the corners of the decision point grid, far away from the one bore that did encounter contamination. Experience suggests that this residual uncertainty in the corners of the grid is a spurious result of Plume ${ }^{\mathrm{TM}}$ 's methodology, given the fact that clean bores separate these areas from the bore with contamination. If Plume ${ }^{\mathrm{TM}}$ were to select bore number 12 , it might examine these corners to remove this residual uncertainty. On the basis of the graphics in Figure 11, however, a technical staff person would probably focus on the areas immediately adjacent to PB-6.

Figure 12 consists of two graphs. The first shows the benefit expected from each bore sunk and the actual impact observed. Note that for most bores, these two values are the same, reflecting the fact that what the bores encountered was what was expected. Only bore PB-6 encountered unexpected contamination. A significant decrease in the impact of bores occurs after installation of the ninth. After the eleventh bore, the impact drops to less than $50 \%$ of the impact obtained from each of the first nine bores. The reason is that for the first nine bores there existed large contiguous uncertain soil volumes that could be reclaimed by sampling. After the eleventh bore, however, the additional benefit in uncertainty reduction is based on further delineation of the contamination encountered by PB-6. The second graph shows the volumetric classification of soils at the $80 \%$ certainty level as the program progressed. The black line in this figure indicates the best guess for the volume of soil that is contaminated.

\subsection{IMPACT OF SPATIAL AUTOCORRELATION RANGE}

If one assumes a spatial autocorrelation range of $45 \mathrm{ft}$, rather than $35 \mathrm{ft}$ as assumed in the base case, the impacts on the progress of the sampling program are dramatic. Figure 13 shows how the adaptive sampling program would have developed with this spatial autocorrelation range, along with the lateral extent of contamination at a depth of $20 \mathrm{ft}$. The lateral area defined by the decision point grid is grey-shaded to represent the probability of contamination at a depth of $20 \mathrm{ft}$. The shading runs from white (no contamination present) to black (contamination known to exist). Nine soil bores are ultimately installed, with only one encountering contamination. These nine bores taken together reduce the volume of soils classified as uncertain at the $80 \%$ level from $100 \%$ at the outset of the sampling program to $22.6 \%$ after completion of the ninth bore. This provides an average impact of $8.6 \%$ uncertainty reduction per bore.

Figure 14 consists of two graphs. The first shows the benefit expected from each bore sunk and the actual impact observed. Again, for most bores, these two values are the same, reflecting the fact that what the bores encountered was what was expected. Only bore PB-6 encountered unexpected contamination. The impact expected from new borings dropped 
significantly after the fifth bore, and then again after the ninth bore. The second graph shows the volumetric classification of soils at the $80 \%$ certainty level as the program progressed. The black line in this figure indicates the best guess for the volume of soil that is contaminated.

The immediate issue when confronted with a new sampling situation is the proper spatial autocorrelation range to be assumed. In the case of Plume ${ }^{\mathrm{TM}}$, the spatial autocorrelation range is closely linked to the assumed width of contamination that one is trying to determine. In this regard, at least initially, the assumed spatial autocorrelation range functions much as the diameter of contamination used in the probabilistic buried object search algorithms described by Singer $(1972,1975)$ and Gilbert (1987). Note that in the case of the 60 s pits, the data initially generated by samples would not contribute significantly to the derivation of the true variogram for this site because the first set of bores was clean. In fact, in the case of adaptive sampling programs, the use of initial sampling data for the development of variograms can be misleading because the objectives of the program (i.e., to maximize the area known to be clean) might slant sampling toward results that would not be representative of the site as a whole.

By increasing the assumed spatial autocorrelation range from 35 to $45 \mathrm{ft}$, nine bores produced a greater reduction in uncertainty than the original eleven. However, if one believed that the contaminated areas of concern were smaller than $45 \mathrm{ft}$ in width, then this uncertainty reduction is misleading.

\subsection{IMPACT OF INITIAL SOFT INFORMATION}

In the 60s pits area, we have engineered drawings showing the original intended locations of the 60 s pits. This information can be used to build an initial conceptual image of probable contaminant location that is captured in the prior probability density functions at each decision point. Changing the initial conceptual image of where contamination might be has a direct impact on subsequent sampling. Figure 15 shows the progress of an adaptive sampling program predicated on an initial conceptual image that takes into account the 60s pits engineering drawings and also shows the lateral extent of contamination at a depth of $20 \mathrm{ft}$ based on sampling program results. As Figure 15 illustrates, the availability of soft information regarding probable contaminant location has a significant impact both on the number of bores required to delineate the contamination and on the course of the sampling program. In this adaptive sampling program, nine bores are installed, with one encountering contamination. These nine bores reduce the initial volume of soil classified as uncertain at the $80 \%$ level from $100 \%$ to $28.2 \%$. This translates to an average of $8 \%$ uncertainty reduction per bore installed.

Figure 16 consists of two graphs. The first shows the benefit expected from each bore sunk and the actual impact observed. Again, for most bores, these two values are the same, reflecting the fact that what the bores encountered was what was expected. Only bore PB-9 encountered unexpected contamination. The impact expected from new borings dropped significantly after the ninth bore. The second graph shows the volumetric classification of 
soils at the $80 \%$ certainty level as the program progressed. The black line in this figure indicates the best guess of the volume for soil that is contaminated.

\subsection{IMPACT OF SAMPLING PROGRAM GOALS}

Not surprisingly, altering the goals of a sampling program can also directly alter the course and outcome of the program. For the final adaptive sampling program scenario, it was assumed that the goal of the sampling program was to minimize the uncertainty associated with the volumetric classification of soils at the $70 \%$ certainty level, rather than at the $80 \%$ level as in the base case. This is equivalent to tolerating a greater level of potential error when individual decision points are classified as either clean or contaminated. Figure 17 shows the course of the adaptive sampling program under this scenario, as well as the lateral extent of contamination at a depth of $20 \mathrm{ft}$ based on sampling program results. Eleven bores are installed, with one encountering contamination. These eleven bores reduce the uncertainty associated with the volumetric classification of soils at the $70 \%$ level from $100 \%$ at the start to only $14.9 \%$ after the eleventh bore. This translates to an uncertainty reduction of $7.7 \%$ per bore installed.

Figure 18 provides two graphs. The first shows the benefit expected from each bore sunk and the actual impact observed. Again, for most bores, these two values are the same, reflecting the fact that what the bores encountered was what was expected. Only bore PB-5 encountered unexpected contamination. The impact expected from new borings dropped significantly after the sixth bore, and dramatically after the eleventh bore. The second graph shows the volumetric classification of soils at the $70 \%$ certainty level as the program progressed. The black line in this figure indicates the best guess of the volume for soil that is contaminated.

\subsection{SAMPLE SPACING ALONG VERTICAL BORES}

The analysis for these various adaptive sampling program scenarios assumed that samples were taken every $5 \mathrm{ft}$ down the length of each bore. This is a typical EPA requirement for soil bores. Figure 19 shows the loss in impact as sample spacing is increased for the base and altered spatial-autocorrelation-range scenarios. This figure clearly indicates that, when one assumes an isotropic variogram with a 35- or 45- $\mathrm{ft}$ range, a 5-ft spacing is considerably narrower than required. The spacing between samples can be significantly increased without significantly decreasing the value of information gained from the bore. In cases where field screening technologies yield inexpensive results relative to the cost of installing a new bore, the little additional information gleaned from a tight sample spacing may be justified. However, if the cost of obtaining a sample is significant relative to the cost of installing a new bore, then sample spacing equal to $5 \mathrm{ft}$ may not be justified or needed. 


\subsection{COMPARISON WITH ACTUAL SAMPLING PROGRAM}

At the 60s pits, what actually happened was the installation of seven vertical bores and two directionally drilled bores in three different sampling programs, with a total of 66 samples collected and 65 sent to the laboratory for chromium analysis. This resulted in a volumetric uncertainty reduction of soils at the $80 \%$ level from $100 \%$ initially to $79.8 \%$. In comparison, the base adaptive sampling program scenario assumed eleven bores would be installed, a total of 154 samples collected and analyzed with a field screening technique such as XRF or ASV, and a volumetric uncertainty reduction of soils at the $80 \%$ level from $100 \%$ to only $33.4 \%$. If one had based an adaptive sampling program on the little soft information that was available for the site, one could have reduced the number of bores to nine and still reduced the volume classified as uncertain at the $80 \%$ level to only $28.2 \%$. An adaptive sampling program that exploited the soft information present would have required only one trip to the field instead of three and, for the same number of bores, would have provided 3.5 times as much information.

\subsection{CONTAMINATION IDENTIFICATION VS. DELINEATION}

Sampling for site characterization is really a two-step process. The first step involves determining whether contamination is present above some prespecified threshold, and the second is determining the extent of contamination, if it does exist. The four adaptive sampling programs described here basically fall into the first category. They all identified contamination, but stopped short of fully delineating the contamination present. The break point that differentiates when identification stops and delineation starts in an adaptive sampling program is when the expected value of information gained begins to decrease. In the case where uncertainty is being minimized, this reflects the fact that the sampling program can no longer identify large contiguous areas of uncertainty that new bores can remove, and the program must now focus on the relatively much smaller uncertainty associated with the exact boundaries of contamination.

Figure 20 shows an extension of the third adaptive sampling program scenario in which the soft information regarding pit locations is used to condition the sampling program's progress. Bore placement begins where Figure 16 ends, with bore PB-10, and shows how this program would have proceeded for an additional nine borings. The red irregular polygon in each of the images denotes the actual extent of contamination at a depth of $20 \mathrm{ft}$, the green irregular polygon encloses the area with probability of contamination greater than 0.5 , and the blue irregular polygon encloses the area with probability of contamination greater than 0.2 based on Plume ${ }^{\mathrm{TM}}$ 's analysis of the available data. Note that, once again, SitePlanner ${ }^{\mathrm{TM}}$ provides a qualitative check of Plume ${ }^{\mathrm{TM}}$ 's analysis. As the sampling program progresses, residual uncertainty is left along the edges and in the corners of the decision point grid. However, because of the spatial locations of bores that were completely clean, this residual uncertainty is likely an artifact of Plume ${ }^{\mathrm{TM}}$ 's analysis. Consequently, the discussion and analysis that follows focuses on the uncertainty in soil classification found in the center of the grid, between bores that are known to be clean and those that have encountered contamination. 
Given the relatively small impact of these bores on the total volume of soils classified as uncertain at the $80 \%$ level, one might ask if their installation is justified. Contaminant delineation typically serves two functions: first, it provides a gross estimate of the amount of contamination present and, second, it provides information about exactly which soils are contaminated and which are not, i.e., the exact location of contamination. To answer the first question, a conservative regulator or responsible party would focus on those volumes of soil that could be classified as clean at some given probability level. For example, in the case of the 60 s pits, the criterion might be to classify all soils that have a probability of contamination greater than 0.2 as requiring remediation for the purposes of remedial action design. Figure 21 shows the expected and observed value of information obtained as the program progresses and the classification of soils at the $80 \%$ level. The first nine bores reduced the volume of soil classified as uncertain at the $80 \%$ level from $100 \%$ to $28.2 \%$, or a reclassification of $71.8 \%$ of the subsurface soils. In contrast, the next nine bores resulted in a further reclassification of only $4.2 \%$ of the subsurface soils. As Figure 21 illustrates, not only was the expected value of information for each of the last nine bores greatly reduced from the first nine, but also the observed impact often reflected the fact that what was found was not what was expected.

However, if one were interested in determining exactly which soils were contaminated and which were not, then the additional bores do provide additional value. Figure 23 compares the actual volume of soil that is contaminated beneath the 60 s pits with the soil that would be classified as requiring remedial action at the $80 \%$ certainty level as the adaptive sampling program progresses. The soils classified as requiring remedial action at each step of the sampling program can be divided into two categories: those actually contaminated and those actually clean. The perfect sampling program would correctly identify as contaminated only and all of the soils that are truly contaminated. In reality, soil classification will always miss some soils that should have been classified as contaminated but were not (Type I error), and some soils that should have been classified as clean but were labeled as contaminated (Type II error). The former error is of primary concern to regulators because areas with potential human health risks are missed. The latter is of primary concern to the responsible party because it represents areas that were remediated unnecessarily.

For the $60 \mathrm{~s}$ pits, $5,500 \mathrm{yd}^{3}$ of underlying soils are contaminated with chromium above background levels. Initially, at the $80 \%$ level, all $94,800 \mathrm{yd}^{3}$ of soil beneath the 60s pits would be classified as requiring remedial action. This number includes all of the contaminated soil (no Type I errors), as well as $89,300 \mathrm{yd}^{3}$ of soil that is actually clean. From the regulator's perspective, this means no missed human health risks; from Sandia's perspective, this means remediating more than 17 times as much soil as is necessary. After the first nine bores, the volume of soil classified as requiring remediation at the $80 \%$ level is reduced to $15,100 \mathrm{yd}^{3}$. From Sandia's perspective, the amount requiring remediation is reduced by $79,700 \mathrm{yd}^{3}$, a potentially significant remedial action cost savings. From a regulator's standpoint, however, this volume misses almost $37 \%$ of the actual contaminated soil. 
The next three bores have no impact on the total amount of soils classified as requiring remedial action. However, from a regulator's perspective, this new volume of soil misses only $13 \%$ of the actual contaminated volume, a substantial reduction in residual human health risk. The next three bores reduce the volume of soil classified as requiring remediation at the $80 \%$ level from 15,100 to $10,600 \mathrm{yd}^{3}$, a 4,500 -yd $\mathrm{d}^{3}$ reduction in the total amount of soil that needs to be addressed. This new volume of soil misses approximately $19 \%$ of the $5,500 \mathrm{yd}^{3}$ of actual contaminated soil. The final three bores slightly increase the volume of soil classified as requiring remediation to $11,400 \mathrm{yd}^{3}$. However, in doing so these bores capture virtually all of the actual contaminated soil, 5,300 $\mathrm{yd}^{3}$. 


\section{CONCLUSIONS}

On the basis of the data that have been collected from nine vertical and directionally drilled bores in the vicinity of the 60 s pits, the best estimate for the volume of soils contaminated with chromium above background levels is $5,500 \mathrm{yd}^{3}$. However, if one were to be conservative and include all soils that have greater than $20 \%$ chance of being contaminated, the volume increases to $74,000 \mathrm{yd}^{3}$. This estimate is based on an assumed spatial autocorrelation range of $35 \mathrm{ft}$, as observed from the collected data. The latter number emphasizes the relatively large degree of uncertainty associated with the best estimate of contaminated soil volume for this site. This uncertainty is largely a product of the paucity of hard sampling data north and northeast of the 60s pits area, as well as at depth directly beneath the area where contamination was encountered by the directionally drilled bores. This uncertainty suggests that if a goal of site characterization in the vicinity of the 60s pits were to clarify the position and extent of subsurface chromium contamination, there would be significant value in locating at least one new bore in the center of the contaminated area to better ascertain total depth of contaminant penetration and a second bore northeast of the 60 s pits area to better define contamination extent in this direction.

The retrospective analysis of the 60s pits area with an adaptive sampling program approach suggests that, in the case of the $60 \mathrm{~s}$ pits, a dramatic refinement in contamination delineation would have occurred if an adaptive sampling program had been used at the onset. If an adaptive sampling program that leveraged the little soft information that was available for this area had been used, the volume of soil classified as requiring remedial action at the $80 \%$ level could have been reduced from 74,000 to only $26,700 \mathrm{yd}^{3}$. With the visualization capabilities of SitePlanner ${ }^{\mathrm{TM}}$, the residual uncertainty associated with the adaptive sampling program that is an artifact of Plume ${ }^{\mathrm{TM}} \mathrm{s}$ analysis is further reduced, and the volume of soils classified as requiring remedial action at the $80 \%$ level decreases to only $15,100 \mathrm{yd}^{3}$ of soil. The conclusion is that with only one sampling program and the same number of bores as were actually installed, an adaptive sampling program at this site would have cut the volume of soils classified as uncertain at the $80 \%$ certainty level by almost four times as much as the three actual sampling programs did.

The retrospective analysis also illustrates the difference between two distinct adaptive sampling program phases: contaminant identification and contaminant delineation. In the first phase, every new bore has the potential for significantly reducing the uncertainty associated with the presence or absence of contamination beneath a site. However, the first phase provides little detailed information regarding exactly which soils are contaminated and which are not. In the second phase, additional bores contribute relatively little to the overall estimates of contaminated volume, but they do clarify exactly where contamination is. 


\section{REFERENCES}

Deutsch, C.V., and A.G. Journel, 1992, GSLIB: Geostatistical Software Library and User's Guide, Oxford University Press, New York.

Gilbert, R.O., 1987, Statistical Methods for Environmental Pollution Monitoring, Van Nostrand Reinhold Company, New York, N.Y.

Johnson, R., 1993a, Adaptive Sampling Strategy Support for the Unlined Chromic Acid Pit, Chemical Waste Landfill, Sandia National Laboratories, Albuquerque, New Mexico, ANL/EAD/TM-2, Argonne National Laboratory, Environmental Assessment Division, Argonne, Ill.

Johnson, R., 1993b, "A Bayesian Approach to Contaminant Delineation," in Proceedings of the 1993 Ground Water Modeling Conference, June 9-12, 1993, Colorado School of Mines Campus, Golden, Colorado, E. Poeter, S. Ashlock, and J. Proud (editors), Colorado School of Mines, Golden, Colo.

Singer, D.A., 1972, "ELIPGRID: A Fortran IV Program for Calculating the Probability of Success in Locating Elliptical Targets with Square, Rectangular and Hexagonal Grids," GeoCom Programs 4:1-16.

Singer, D.A., 1975, "Relative Efficiencies of Square and Triangular Grids in the Search for Elliptically Shaped Resource Targets," Journal of Research of the U.S. Geological Survey 3(2): 163-167. 


\section{APPENDIX A}

SAMPLING RESULTS FOR THE 60s PITS

\begin{tabular}{|c|c|c|c|c|c|c|}
\hline \multirow[b]{2}{*}{ Source } & \multirow[b]{2}{*}{ Name } & \multicolumn{3}{|c|}{ State Planar Coordinates (ft) } & \multirow[b]{2}{*}{ Contaminated $^{\mathrm{a}}$} & \multirow{2}{*}{$\begin{array}{c}\text { Total } \\
\text { Chromium } \\
\text { (mg/kg) }\end{array}$} \\
\hline & & $\mathrm{X}$ & $\mathrm{Y}$ & $\mathrm{Z}$ & & \\
\hline $\mathrm{PE}$ & PE-3 & 414468 & $1.44489 \mathrm{E}+06$ & 5404.5 & 0 & 8 \\
\hline $\mathrm{PE}$ & $\mathrm{PE}-5$ & 414468 & $1.44489 \mathrm{E}+06$ & 5394.5 & 0 & 7.7 \\
\hline $\mathrm{PE}$ & $\mathrm{PE}-7$ & 414468 & $1.44489 \mathrm{E}+06$ & 5384.5 & 0 & 6.3 \\
\hline $\mathrm{T} 10$ & $\mathrm{~T} 10-3$ & 414357 & $1.44487 \mathrm{E}+06$ & 5404.5 & 0 & 11 \\
\hline $\mathrm{T} 10$ & $\mathrm{~T} 10-5$ & 414357 & $1.44487 \mathrm{E}+06$ & 5394.5 & 0 & 5.6 \\
\hline $\mathrm{T} 10$ & $\mathrm{~T} 10-7$ & 414357 & $1.44487 \mathrm{E}+06$ & 5384.5 & 0 & 6.2 \\
\hline $\mathrm{T} 12$ & $\mathrm{~T} 12-3$ & 414314 & $1.44494 \mathrm{E}+06$ & 5404.5 & 0 & 15 \\
\hline $\mathrm{T} 12$ & $\mathrm{~T} 12-5$ & 414314 & $1.44494 \mathrm{E}+06$ & 5394.5 & 0 & 7.1 \\
\hline $\mathrm{T} 12$ & $\mathrm{~T} 12-7$ & 414314 & $1.44494 \mathrm{E}+06$ & 5384.5 & 0 & 7.5 \\
\hline T5 & T5-3 & 414332 & $1.44502 \mathrm{E}+06$ & 5404.5 & 0 & 11 \\
\hline T5 & T5-5 & 414332 & $1.44502 \mathrm{E}+06$ & 5394.5 & 0 & 5 \\
\hline T5 & T5-7 & 414332 & $1.44502 \mathrm{E}+06$ & 5384.5 & 0 & 7.7 \\
\hline $\mathrm{T} 6$ & T6-3 & 414399 & $1.44502 \mathrm{E}+06$ & 5404.5 & 0 & 5.3 \\
\hline T6 & T6-5 & 414399 & $1.44502 \mathrm{E}+06$ & 5394.5 & 0 & 6.2 \\
\hline T6 & T6-7 & 414399 & $1.44502 \mathrm{E}+06$ & 5384.5 & 0 & 4.7 \\
\hline $\mathrm{T} 7$ & T7-5 & 414355 & $1.44498 \mathrm{E}+06$ & 5394.5 & 0 & 7.1 \\
\hline$T 7$ & T7-7 & 414355 & $1.44498 \mathrm{E}+06$ & 5384.5 & 0 & 6.7 \\
\hline T9 & T9-3 & 414295 & $1.44488 \mathrm{E}+06$ & 5404.5 & 0 & 12 \\
\hline T9 & T9-5 & 414295 & $1.44488 \mathrm{E}+06$ & 5394.5 & 0 & 11 \\
\hline T9 & T9-7 & 414295 & $1.44488 \mathrm{E}+06$ & 5384.5 & 0 & 5.4 \\
\hline CWL(170,225) & 4216 & 414394 & $1.44488 \mathrm{E}+06$ & 5409.5 & 0 & 2.8 \\
\hline CWL $(170,225)$ & 4223 & 414394 & $1.44488 \mathrm{E}+06$ & 5379.5 & 0 & 2.9 \\
\hline CWL $(170,225)$ & 4224 & 414394 & $1.44488 \mathrm{E}+06$ & 5369.5 & 0 & 3.3 \\
\hline CWL $(170,225)$ & 4225 & 414394 & $1.44488 \mathrm{E}+06$ & 5359.5 & 0 & 3.2 \\
\hline CWL $(170,225)$ & 4226 & 414394 & $1.44488 \mathrm{E}+06$ & 5349.5 & 0 & 3.2 \\
\hline CWL $(170,225)$ & 4227 & 414394 & $1.44488 \mathrm{E}+06$ & 5339.5 & 0 & 2.4 \\
\hline CWL $(170,225)$ & 4228 & 414394 & $1.44488 \mathrm{E}+06$ & 5329.5 & 0 & 3.9 \\
\hline CWL $(170,225)$ & 4230 & 414394 & $1.44488 \mathrm{E}+06$ & 5319.5 & 0 & 2.4 \\
\hline CWL $(170,225)$ & 4235 & 414394 & $1.44488 \mathrm{E}+06$ & 5299.5 & 0 & 5.8 \\
\hline CWL $(170,225)$ & 4236 & 414394 & $1.44488 \mathrm{E}+06$ & 5279.5 & 0 & 6.7 \\
\hline CWL(170,225) & 4357 & 414394 & $1.44488 \mathrm{E}+06$ & 5259.5 & 0 & 6.2 \\
\hline CWL $(170,225)$ & 4237 & 414394 & $1.44488 \mathrm{E}+06$ & 5239.5 & 0 & 3.7 \\
\hline CWL(170,225) & 4238 & 414394 & $1.44488 \mathrm{E}+06$ & 5219.5 & 0 & 6 \\
\hline CWL(235,231) & 4410 & 414459 & $1.44489 \mathrm{E}+06$ & 5399.5 & 0 & 3.2 \\
\hline S60P65 & S_65 & 414432 & $1.44488 \mathrm{E}+06$ & 5402.68 & 0 & \\
\hline S60P70 & S_70 & 414427 & $1.44488 \mathrm{E}+06$ & 5401.38 & 0 & 6.7 \\
\hline S60P75 & S_75 & 414422 & $1.44488 \mathrm{E}+06$ & 5400.09 & 0 & 4.9 \\
\hline S60P80 & S_80 & 414417 & $1.44488 \mathrm{E}+06$ & 5398.79 & 1 & 29 \\
\hline S60P90 & S_90 & 414408 & $1.44488 \mathrm{E}+06$ & 5396.21 & 1 & 34 \\
\hline S60P100 & S_100 & 414398 & $1.44488 \mathrm{E}+06$ & 5393.62 & 1 & 38 \\
\hline S60P105 & S_105 & 414393 & $1.44488 \mathrm{E}+06$ & 5392.32 & 1 & 18 \\
\hline S60P110 & S_110 & 414388 & $1.44488 \mathrm{E}+06$ & 5391.03 & 0 & 5 \\
\hline S60P115 & S_115 & 414384 & $1.44489 \mathrm{E}+06$ & 5389.74 & 0 & 9.8 \\
\hline S60P120 & S_120 & 414379 & $1.44489 \mathrm{E}+06$ & 5388.44 & 0 & 9.6 \\
\hline S60P125 & S_125 & 414374 & $1.44489 \mathrm{E}+06$ & 5387.15 & 0 & 12 \\
\hline
\end{tabular}




\begin{tabular}{|c|c|c|c|c|c|c|}
\hline \multirow[b]{2}{*}{ Source } & \multirow[b]{2}{*}{ Name } & \multicolumn{3}{|c|}{ State Planar Coordinates $(\mathrm{ft})$} & \multirow[b]{2}{*}{ Contaminated $^{\mathrm{a}}$} & \multirow{2}{*}{$\begin{array}{c}\text { Total } \\
\text { Chromium } \\
(\mathrm{mg} / \mathrm{kg})\end{array}$} \\
\hline & & $\mathrm{X}$ & $\mathrm{Y}$ & $\mathrm{Z}$ & & \\
\hline $\mathrm{S} 60 \mathrm{P} 130$ & S_130 & 414369 & $1.44489 \mathrm{E}+06$ & 5385.85 & 0 & 6.6 \\
\hline S60P135 & $\mathrm{S} \_135$ & 414364 & $1.44489 \mathrm{E}+06$ & 5384.56 & 0 & 5.9 \\
\hline S60P140 & $\mathrm{S} \_140$ & 414359 & $1.44489 \mathrm{E}+06$ & 5383.27 & 0 & 11 \\
\hline S60P145 & $\mathrm{S} \_145$ & 414355 & $1.44489 \mathrm{E}+06$ & 5381.97 & 0 & 7.6 \\
\hline S60P149 & S_149 & 414351 & $1.44489 \mathrm{E}+06$ & 5380.94 & 0 & 14 \\
\hline N60P70 & N_70 & 414427 & $1.44491 \mathrm{E}+06$ & 5401.38 & 1 & 59 \\
\hline N60P80 & N_80 & 414417 & $1.44492 \mathrm{E}+06$ & 5398.8 & 1 & 130 \\
\hline N60P85 & N_85 & 414413 & $1.44492 \mathrm{E}+06$ & 5397.5 & 1 & 110 \\
\hline N60P90 & N_90 & 414408 & $1.44492 \mathrm{E}+06$ & 5396.21 & 1 & 4800 \\
\hline N60P95 & N_95 & 414403 & $1.44492 \mathrm{E}+06$ & 5394.91 & 1 & 1100 \\
\hline N60P100 & N_100 & 414398 & $1.44492 \mathrm{E}+06$ & 5393.62 & 1 & 550 \\
\hline N60P105 & N_105 & 414393 & $1.44492 \mathrm{E}+06$ & 5392.32 & 1 & 42 \\
\hline N60P110 & N_110 & 414388 & $1.44492 \mathrm{E}+06$ & 5391.03 & 1 & 40 \\
\hline N60P115 & N_115 & 414384 & $1.44492 \mathrm{E}+06$ & 5389.74 & 1 & 36 \\
\hline N60P120 & N_120 & 414379 & $1.44492 \mathrm{E}+06$ & 5388.44 & 1 & 45 \\
\hline N60P125 & N_125 & 414374 & $1.44492 \mathrm{E}+06$ & 5387.15 & 0 & 11 \\
\hline N60P130 & N_130 & 414369 & $1.44492 \mathrm{E}+06$ & 5385.85 & 0 & 9.8 \\
\hline N60P135 & N_135 & 414364 & $1.44492 \mathrm{E}+06$ & 5384.56 & 0 & 10 \\
\hline N60P140 & N_140 & 414359 & $1.44492 \mathrm{E}+06$ & 5383.27 & 0 & 13 \\
\hline N60P145 & N_145 & 414355 & $1.44492 \mathrm{E}+06$ & 5381.97 & 0 & 16 \\
\hline N60P150 & N_150 & 414350 & $1.44492 \mathrm{E}+06$ & 5380.68 & 0 & 13 \\
\hline
\end{tabular}

a Total chromium values greater than $16 \mathrm{ppm}$ were classified as contaminated (1); values less than or equal to $16 \mathrm{ppm}$ were classified as clean (0). 
APPENDIX B: ILLUSTRATIONS 


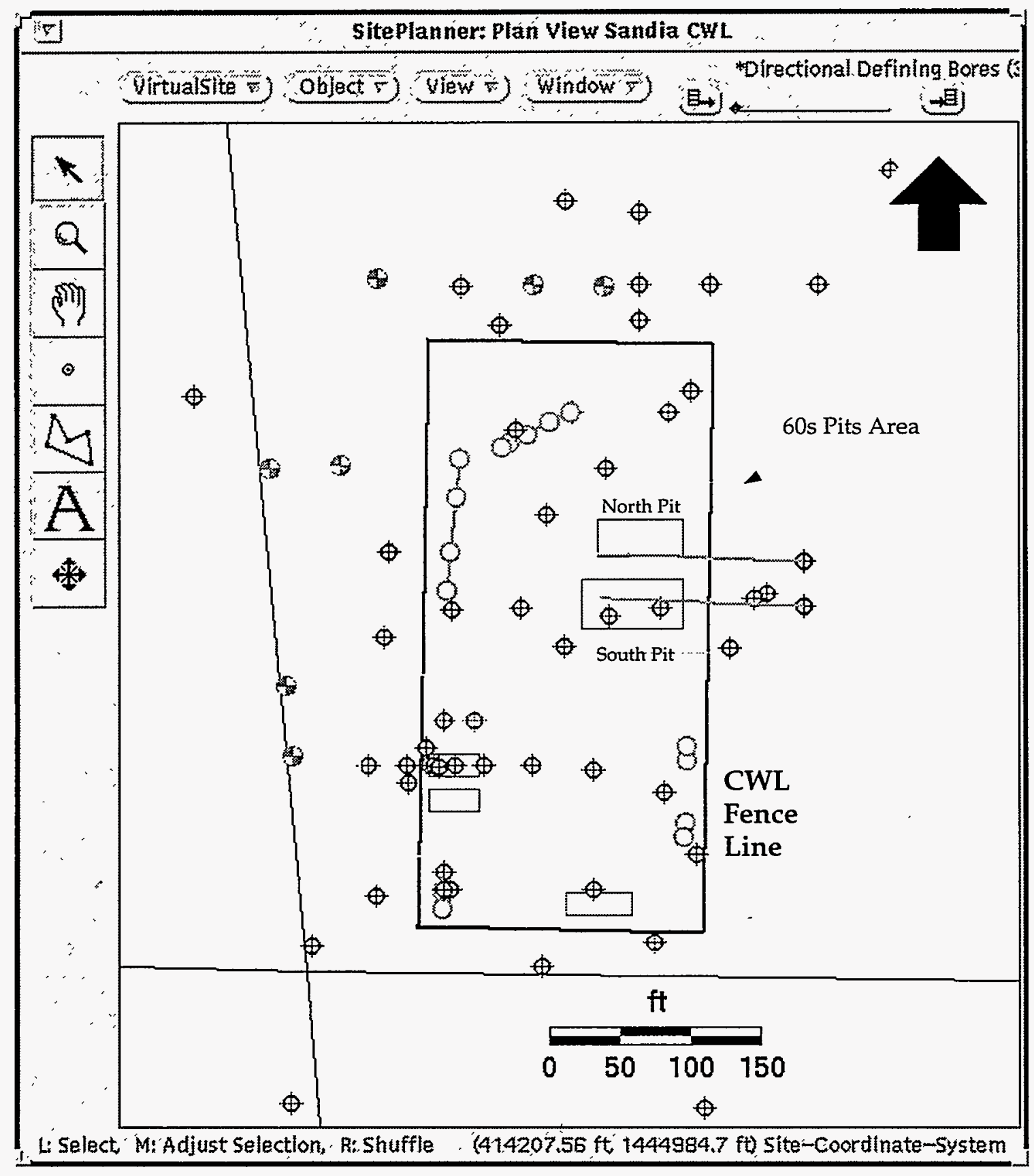

FIGURE 1 Chemical Waste Landfill 


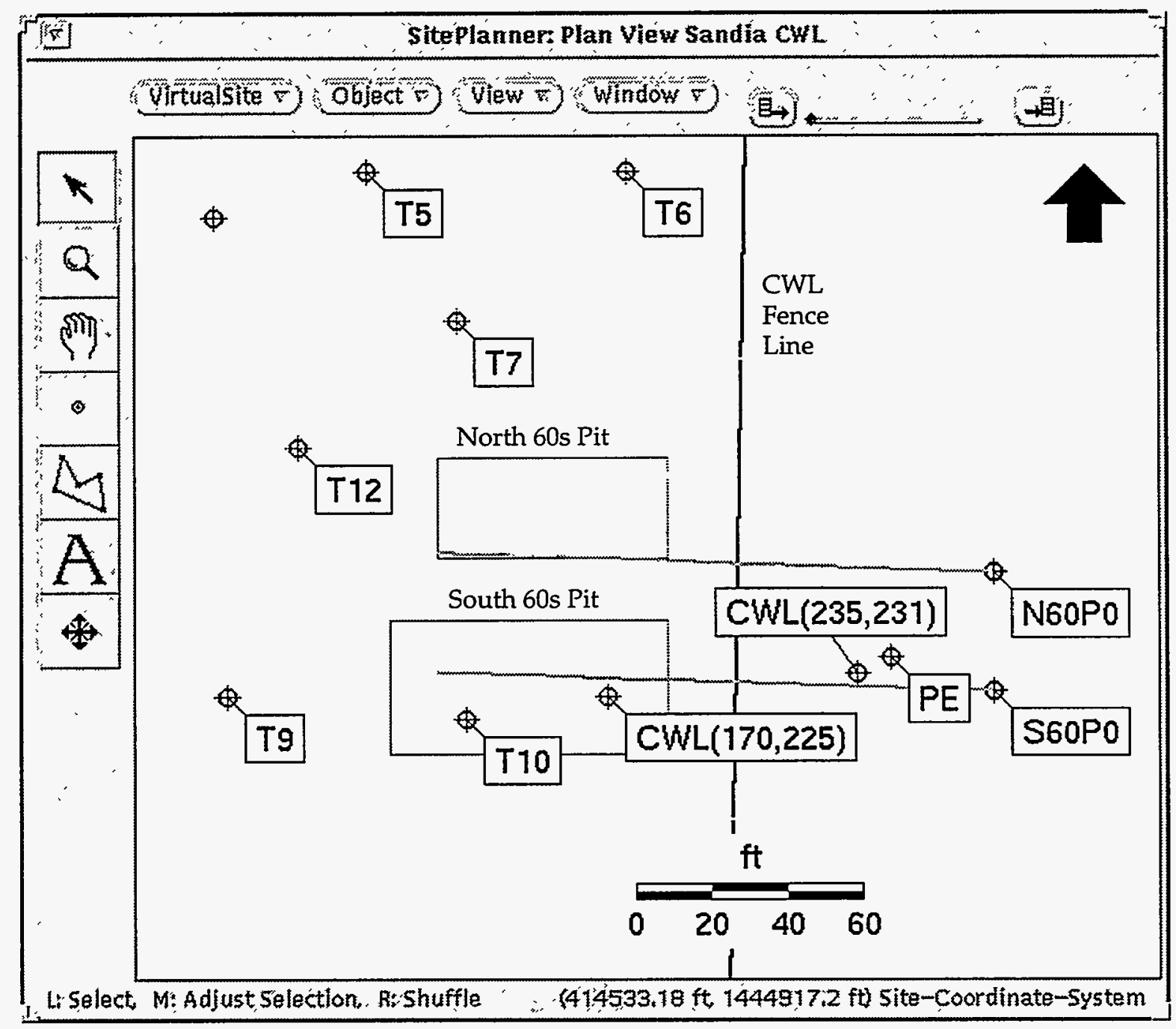

FIGURE 2 Location of 60s Pits Bores with Chromium Data 

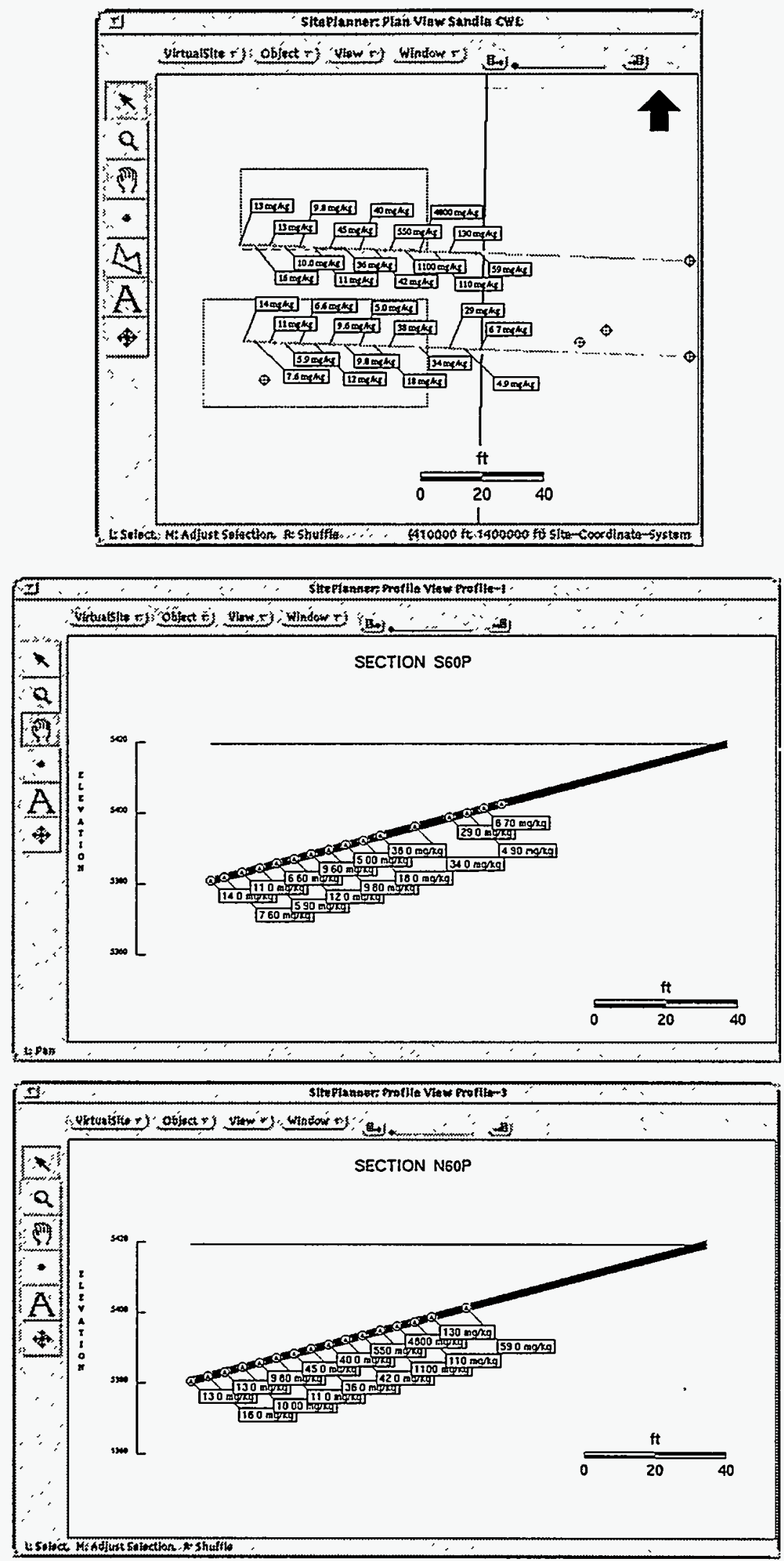

FIGURE 3 Chromium Results (ppm) for Slant Bore Samples 


\section{Covariance}

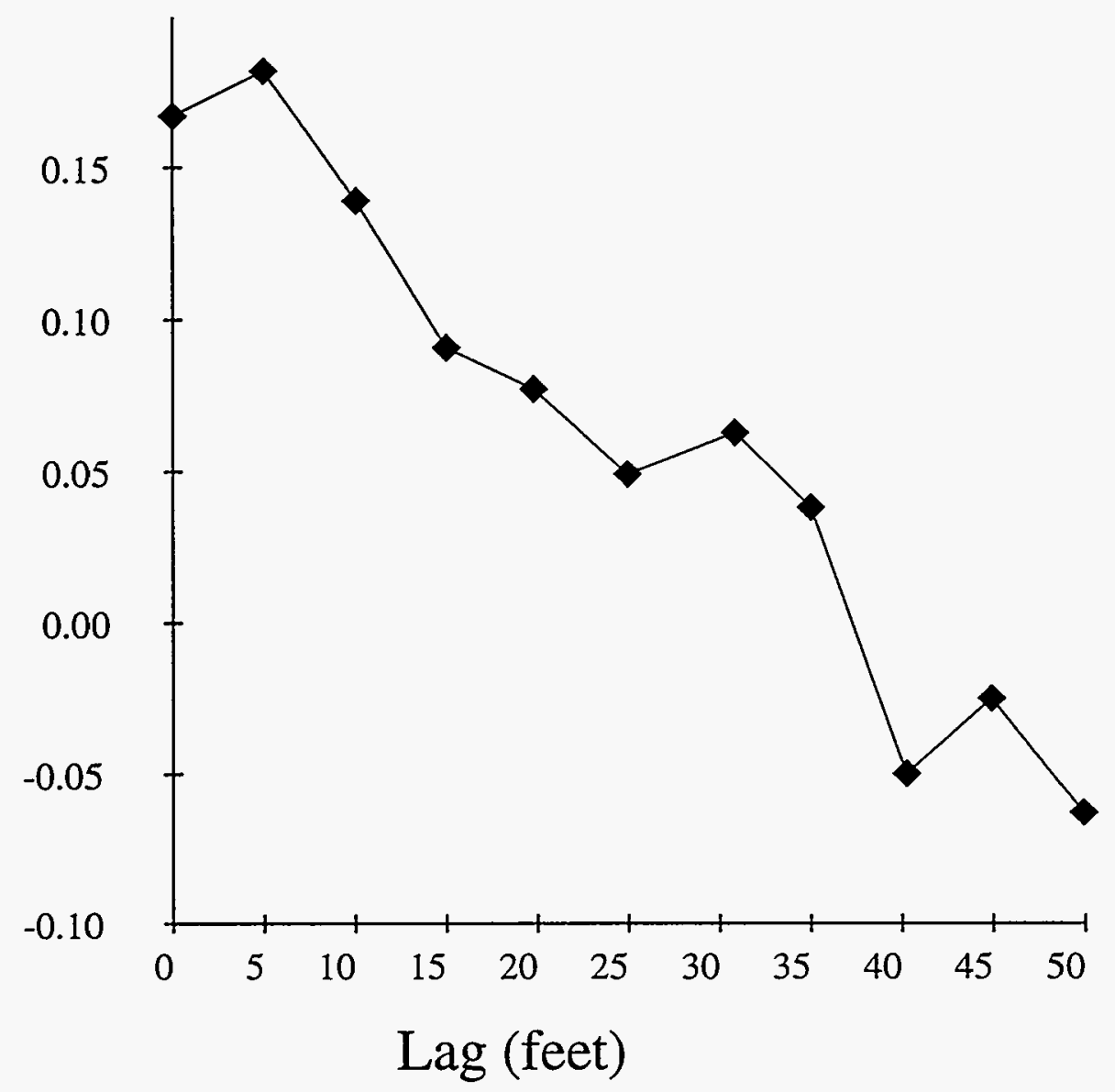

FIGURE 4 Covariance for Total Chromium Indicator Data from 60s Pits Samples 

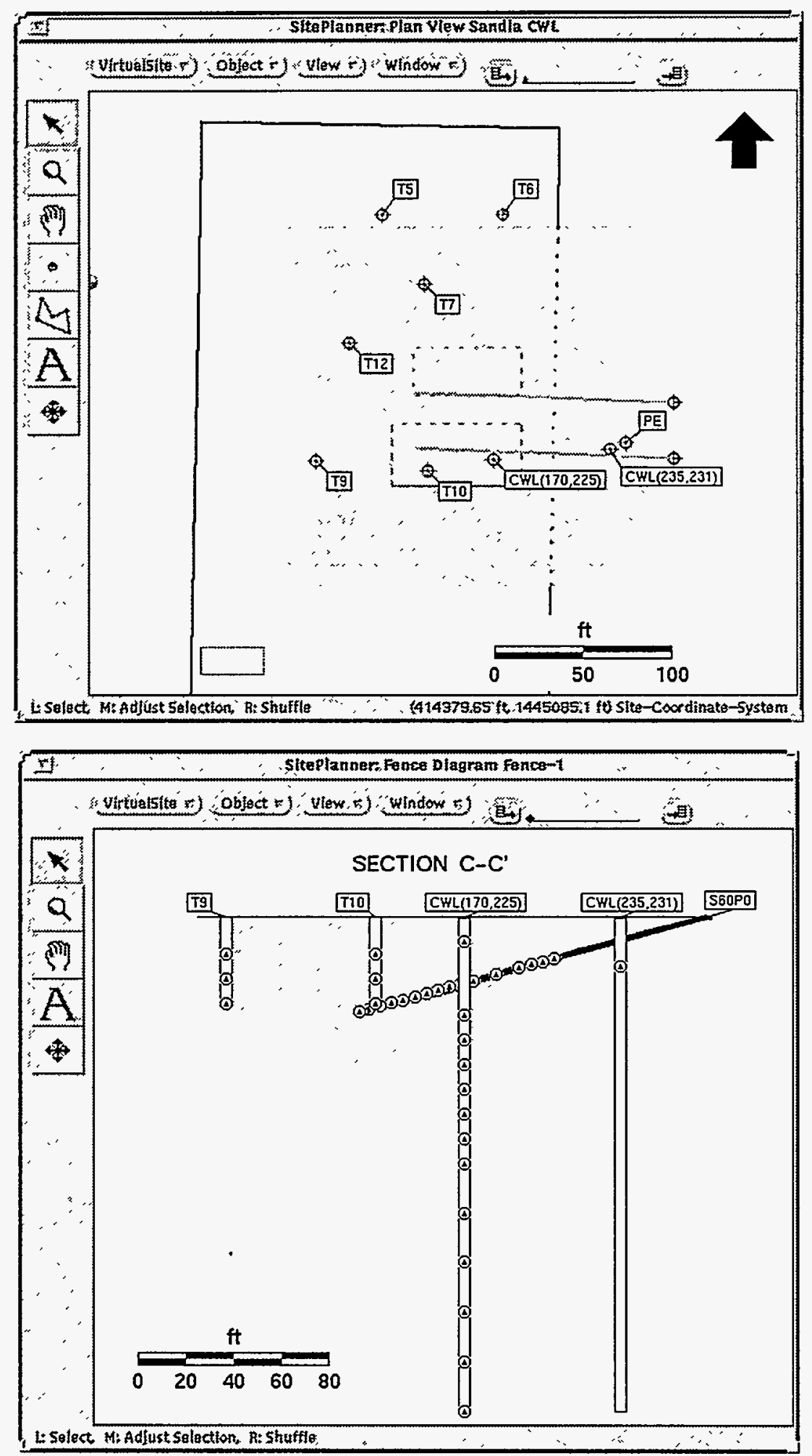

FIGURE 5 Plan and Profile Views of 60s Pits Area Showing Location of Decision Points 

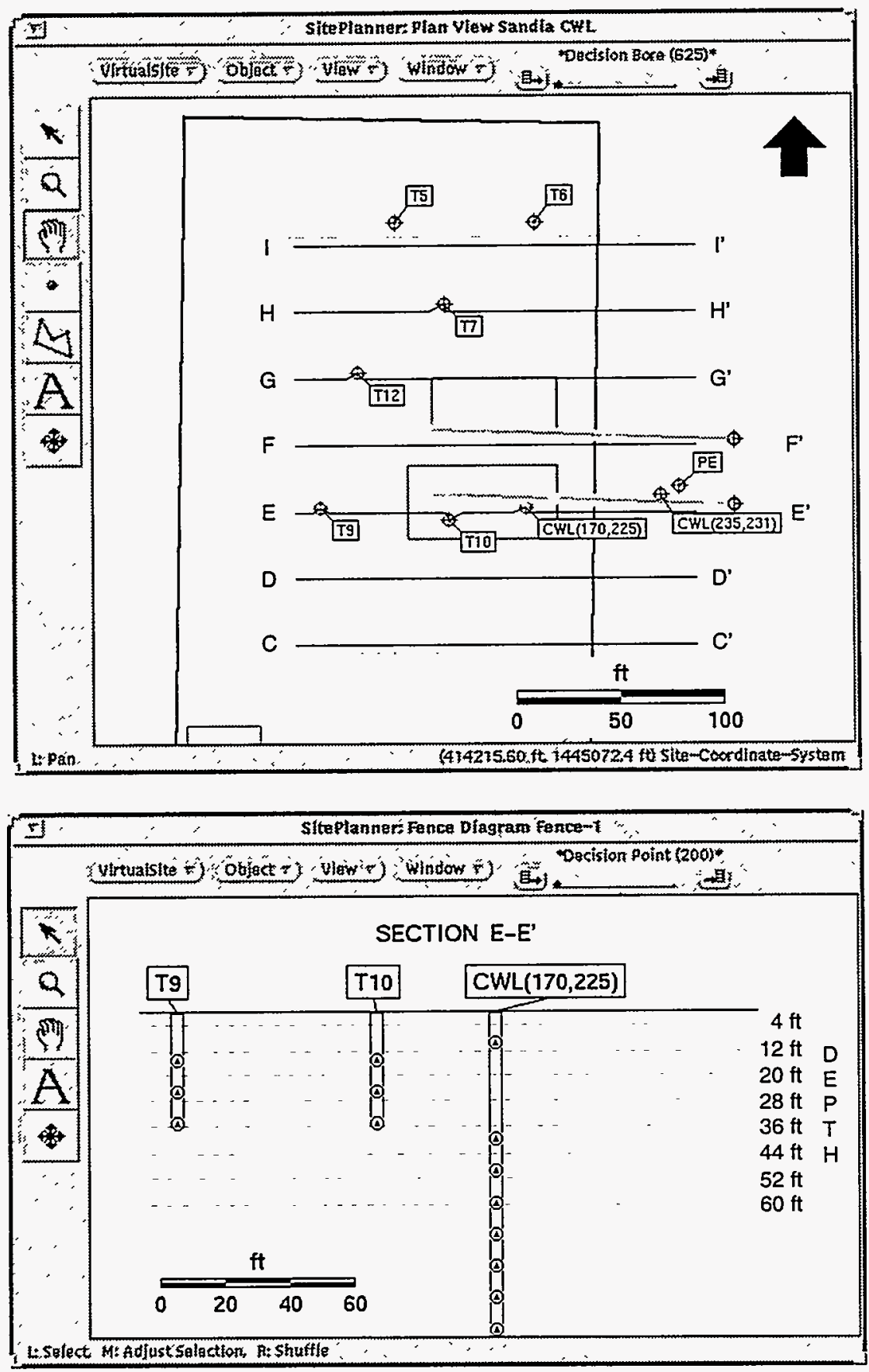

\section{FIGURE 6 Position of Vertical and Lateral Slices}



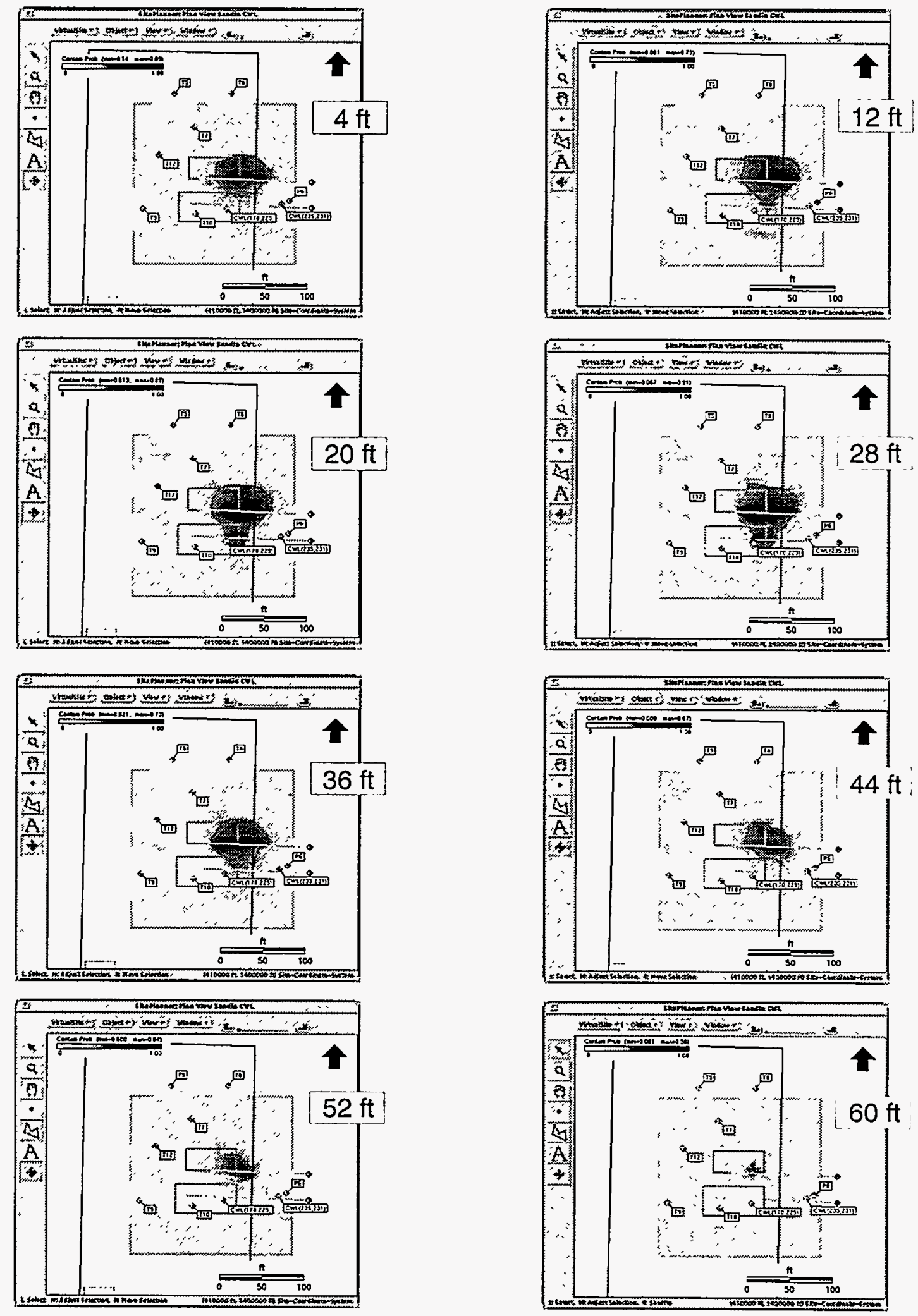

FIGURE 7 Lateral Distribution of Contamination Probability 

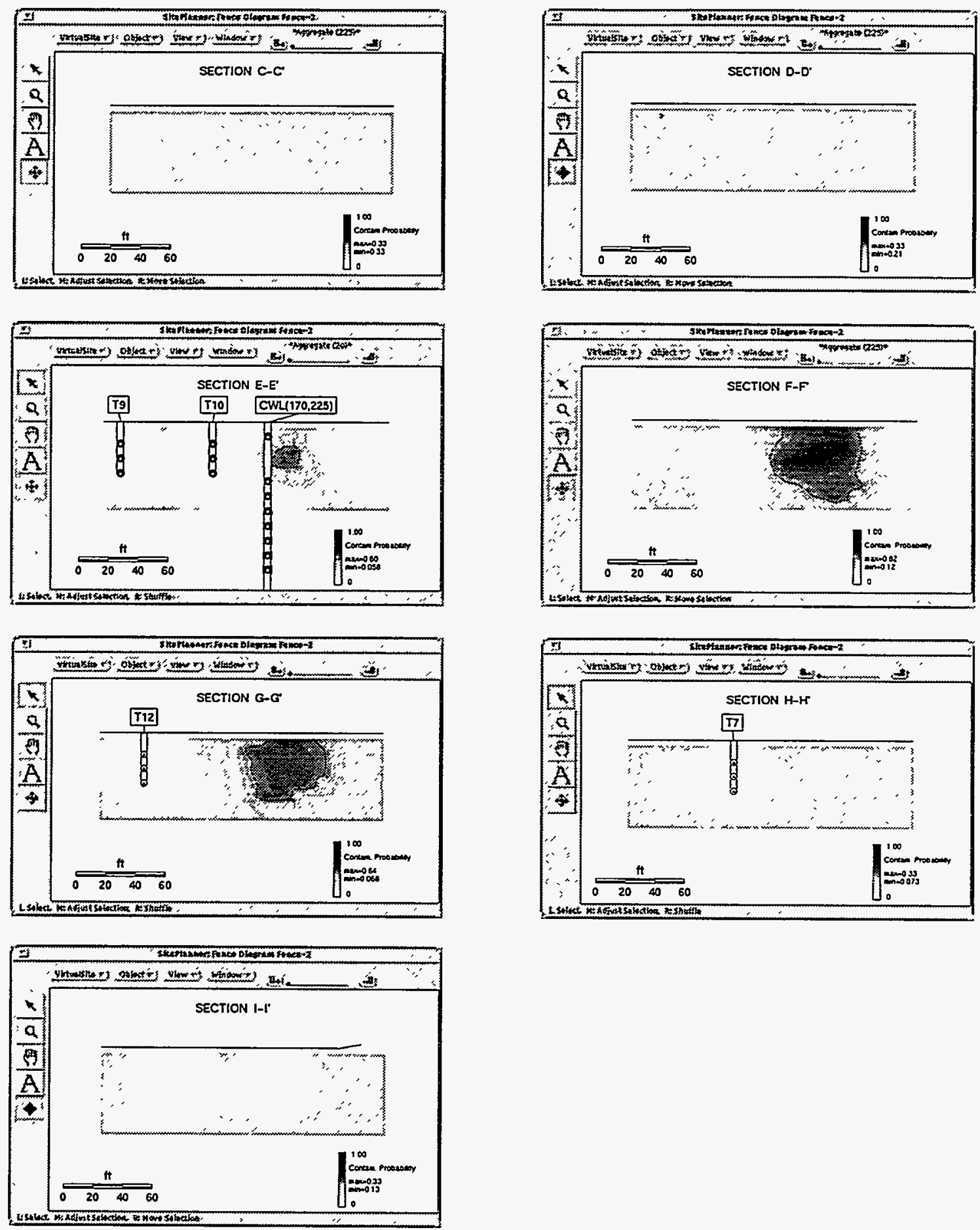

FIGURE 8 Vertical Distribution of Contamination Probability 


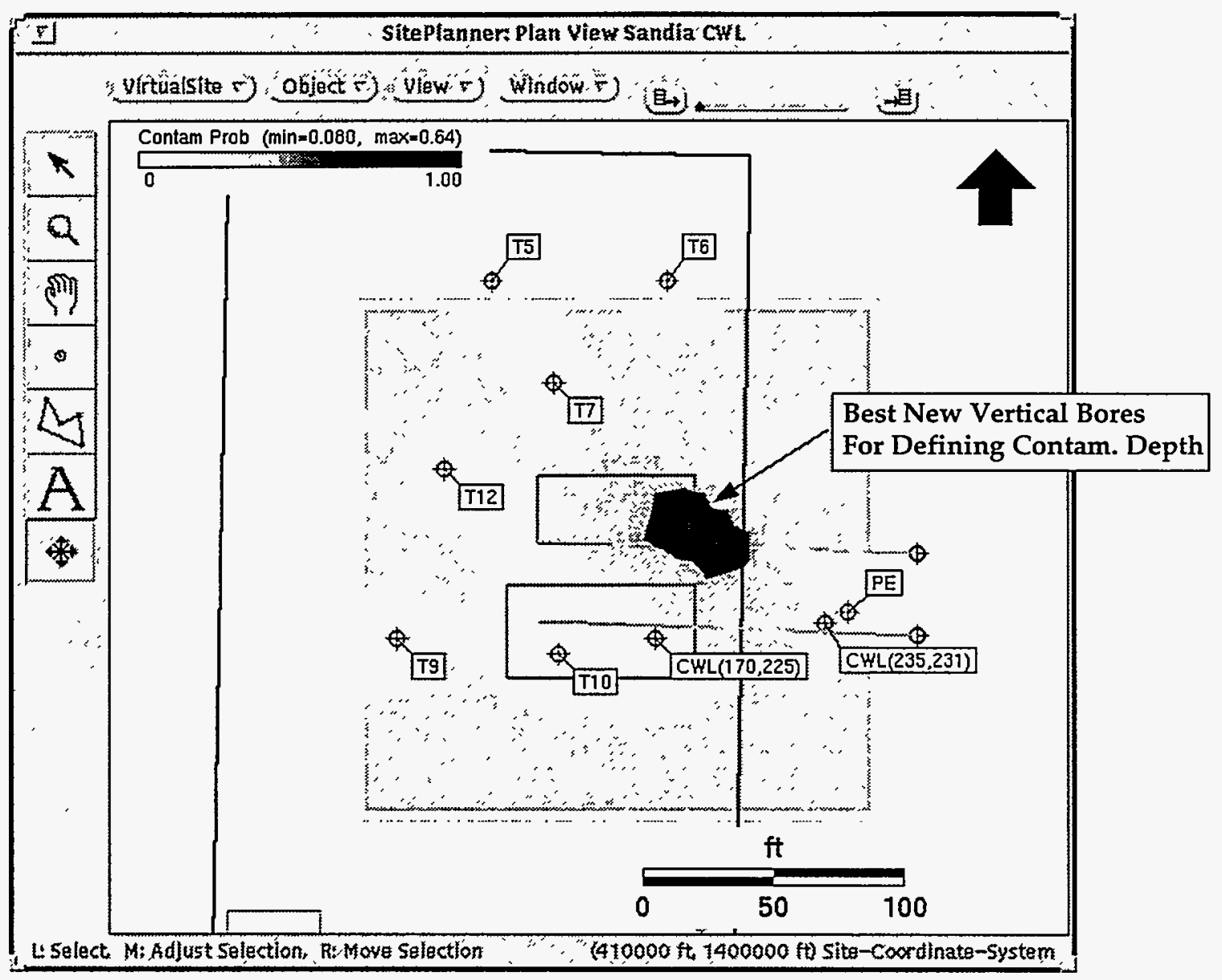

FIGURE 9 Best Vertical Bore Locations for Defining the Vertical Extent of Contamination 


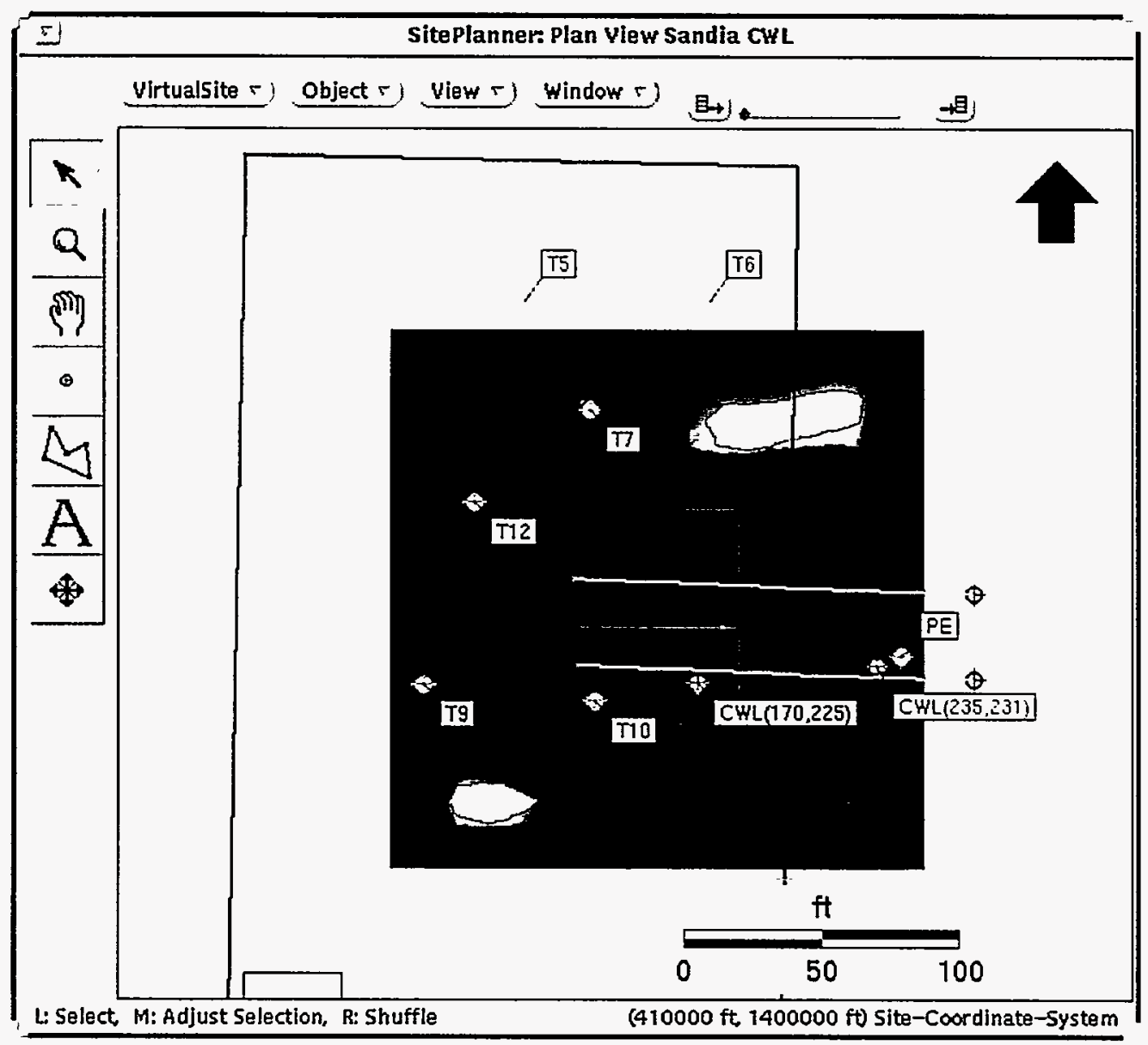

FIGURE 10 Impact Surface for New Vertical Bores 

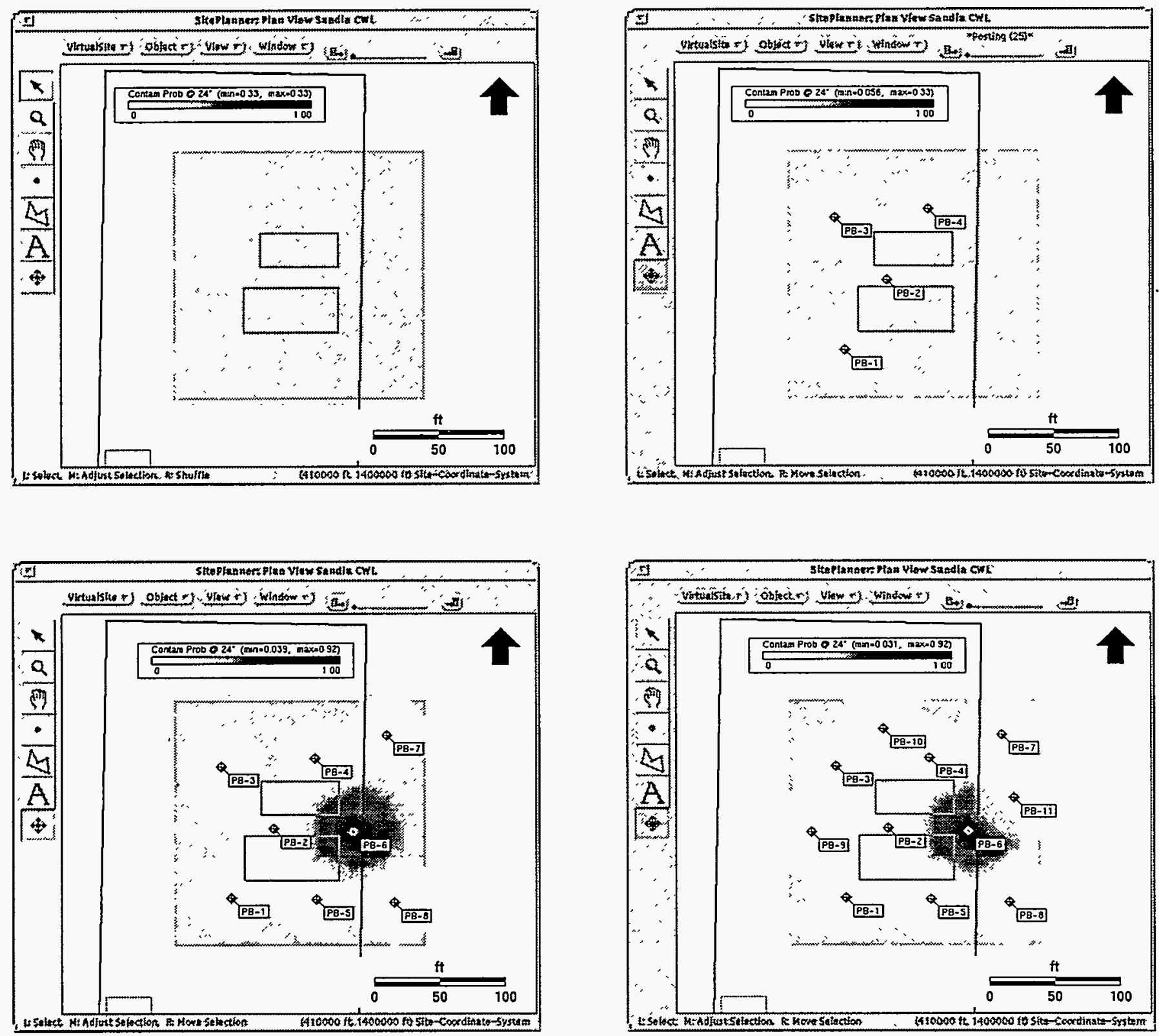

FIGURE 11 Base Case Sampling Program with Lateral Contamination Extent at a Depth of 20 Feet 


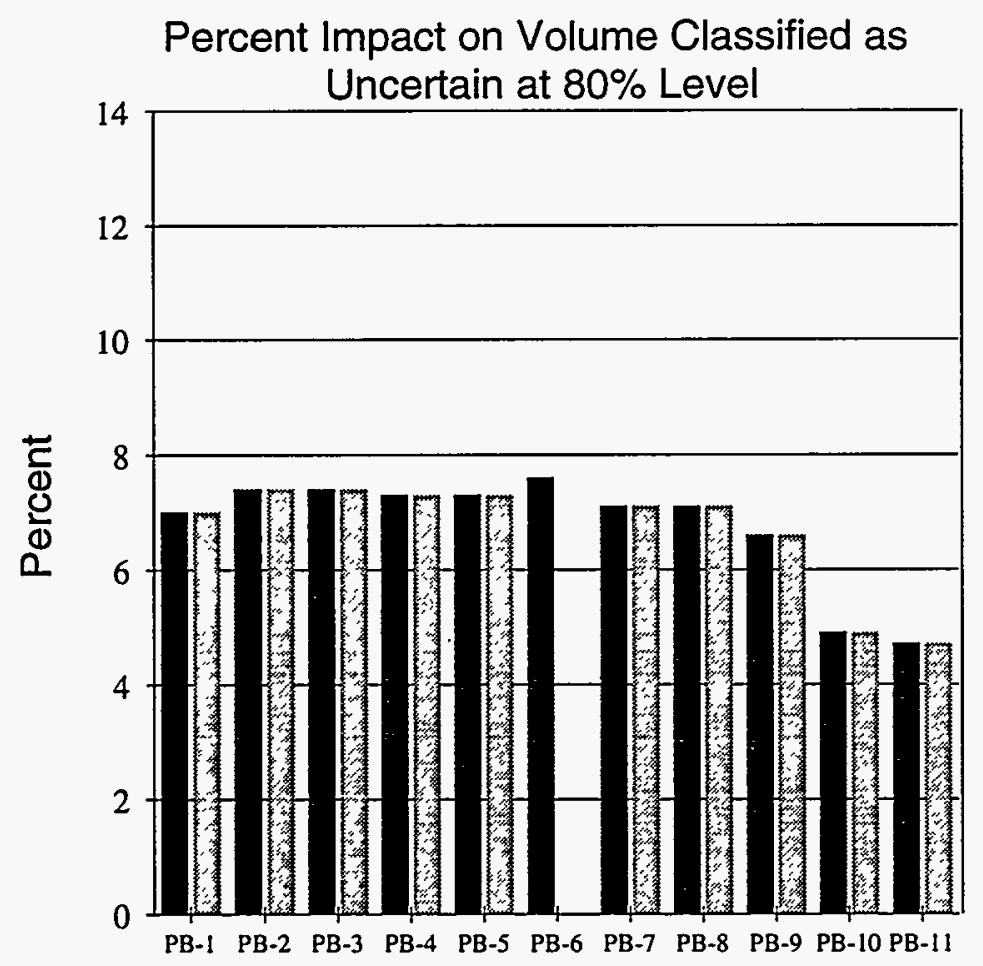

Expected Impact

Observed Impact

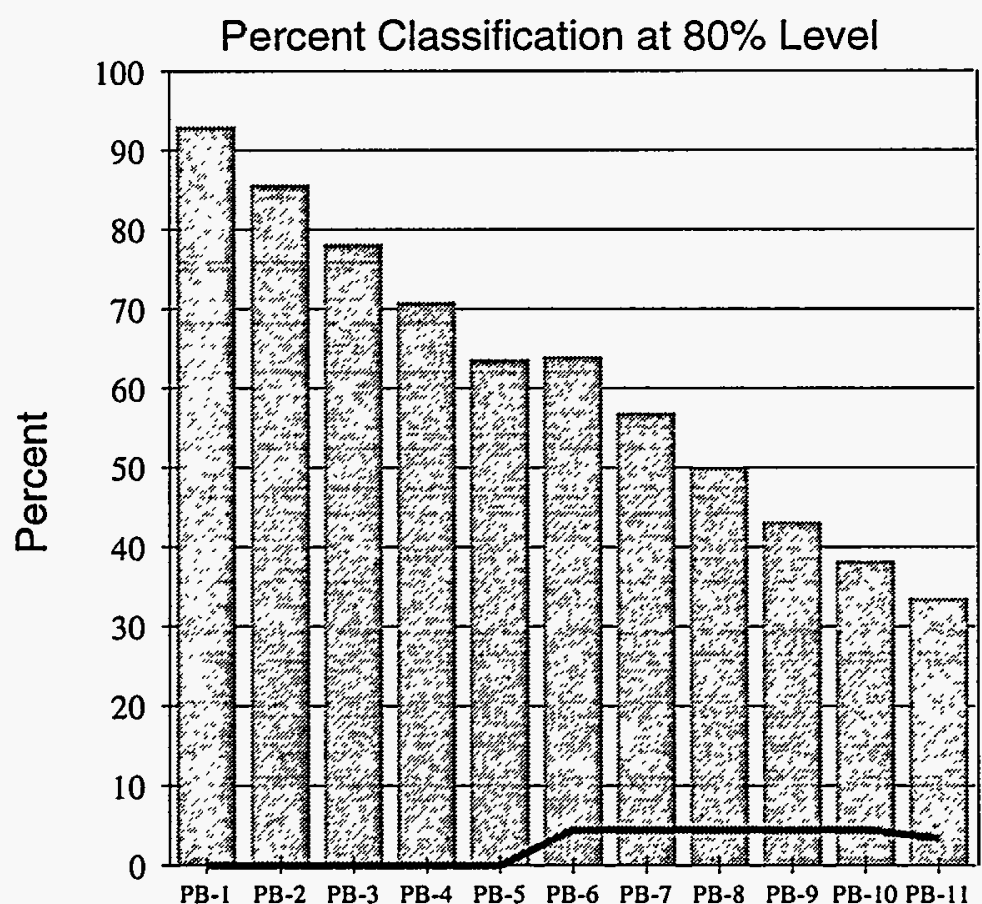

Contaminated

Uncertain

Best Contam Guess

FIGURE 12 Base Case Sampling Program Expected Impact, Actual Impact, and Soil Classification 


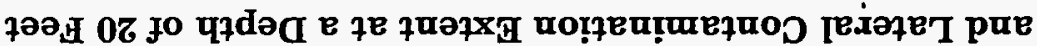

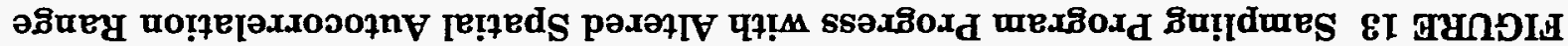
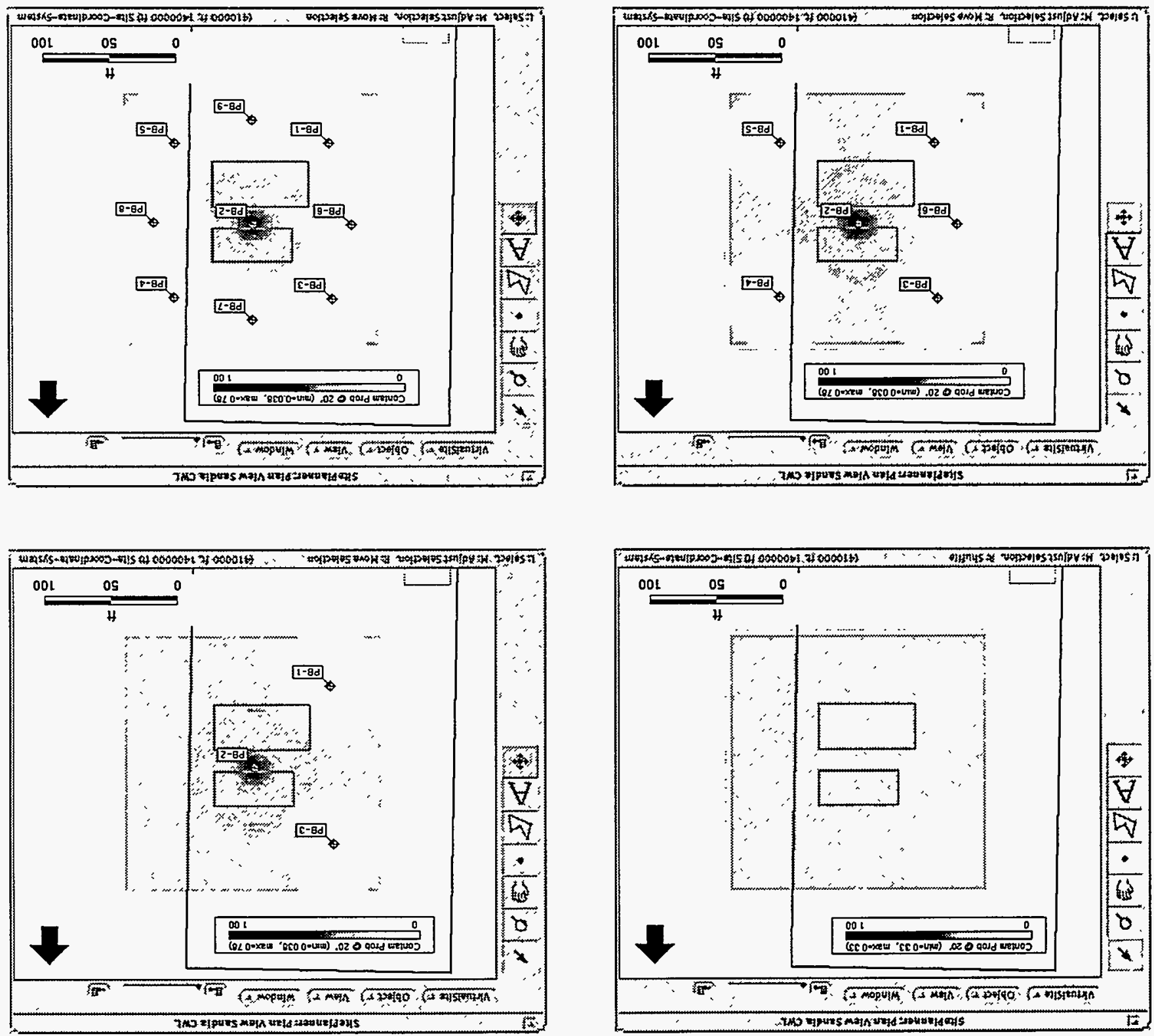
Percent Impact on Volume Classified as Uncertain at $80 \%$ Level

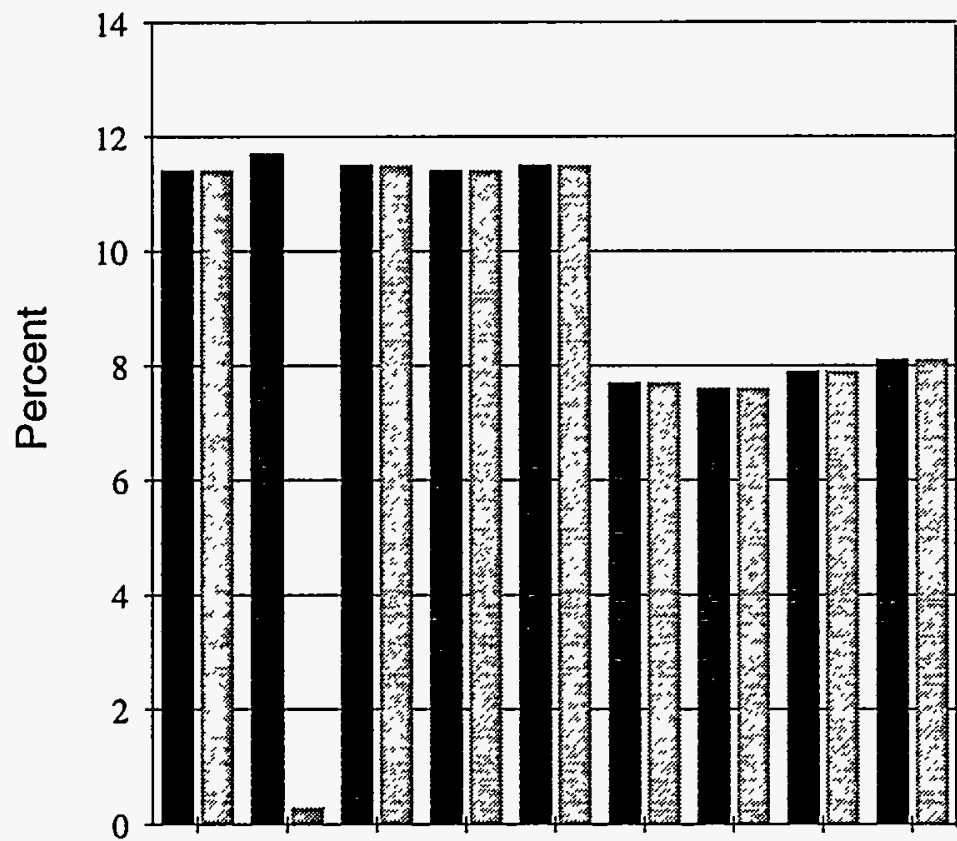

Expected Impact

Observed Impact

PB-1 PB-2 PB-3 PB-4 PB-5 PB-6 PB-7 PB-8 PB-9

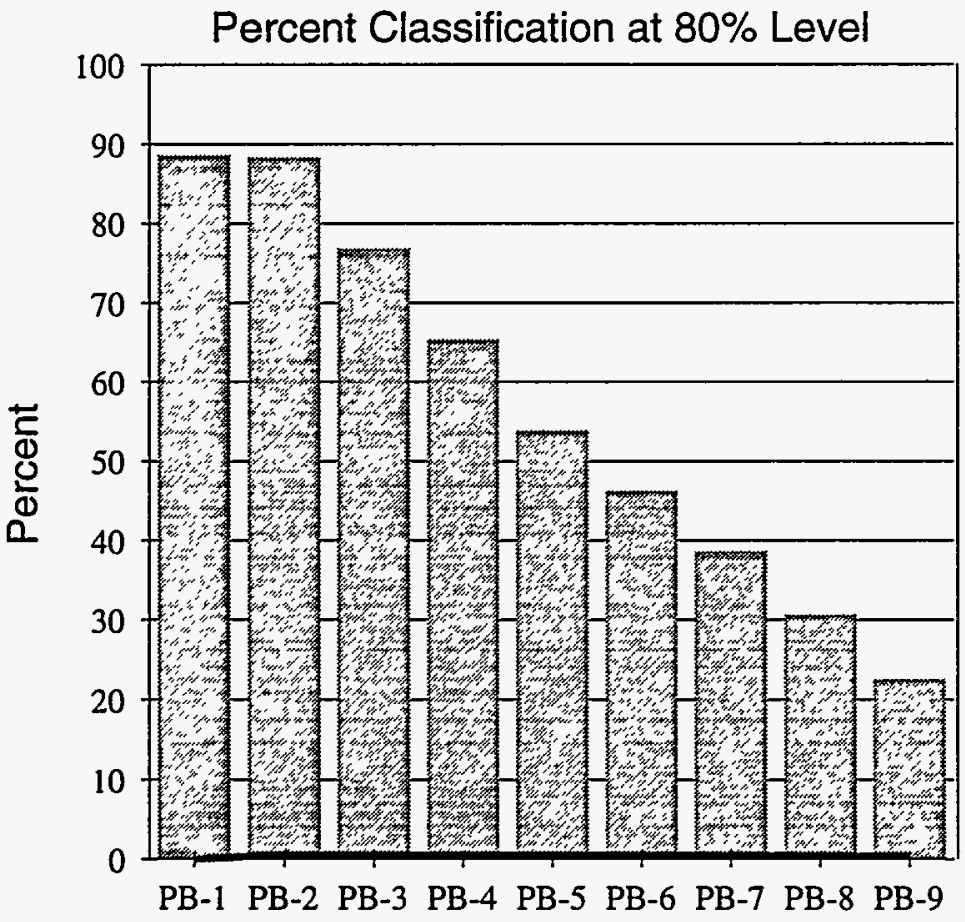

Contaminated

Uncertain

Best Contam Guess

FIGURE 14 Sampling Program Expected Impact, Actual Impact, and Soil Classification for 45-Foot Spatial Autocorrelation Range 

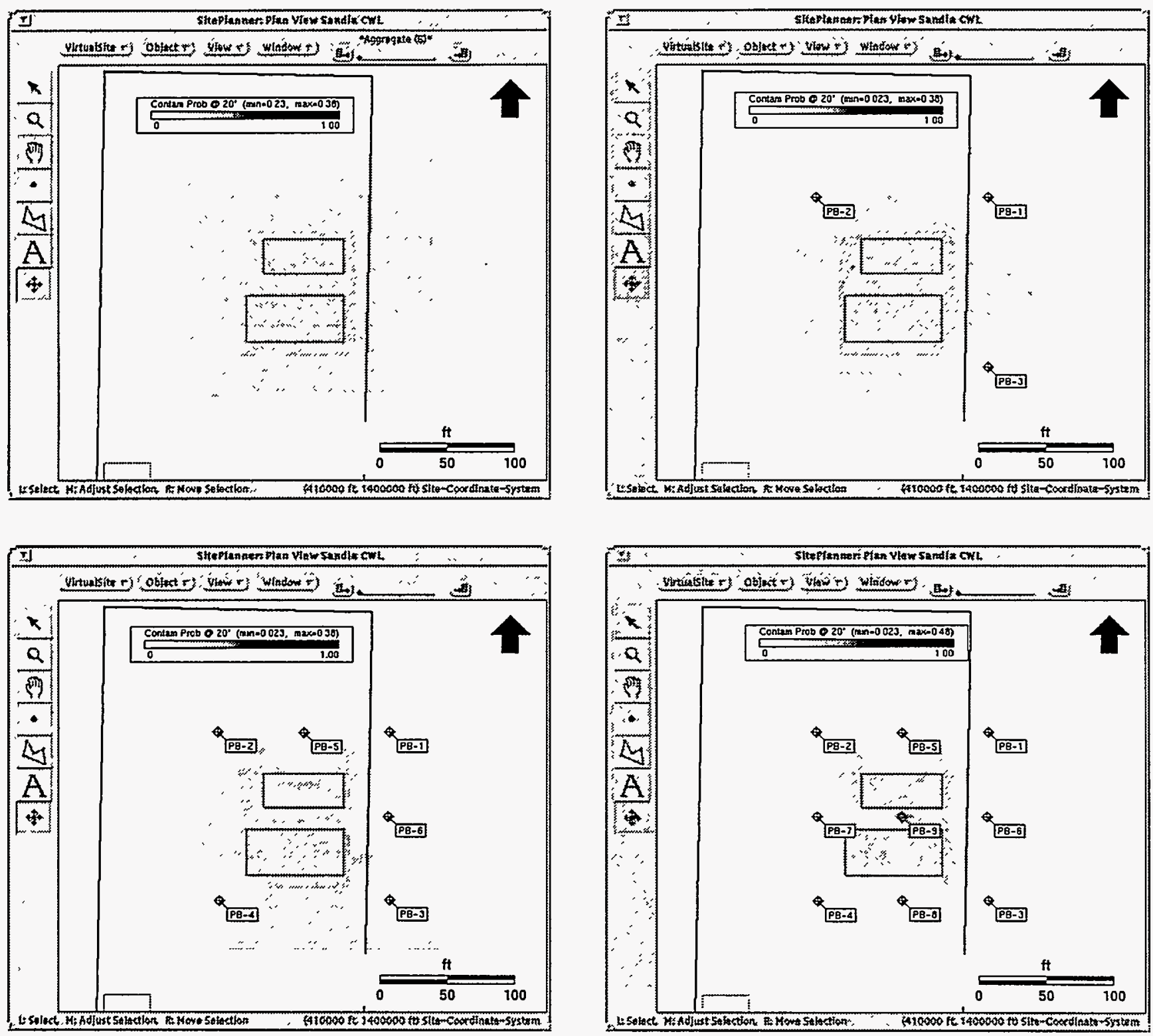

\section{FIGURE 15 Sampling Program Progress with Altered Initial Location Assumptions and Lateral Contamination Extent at a Depth of 20 Feet}




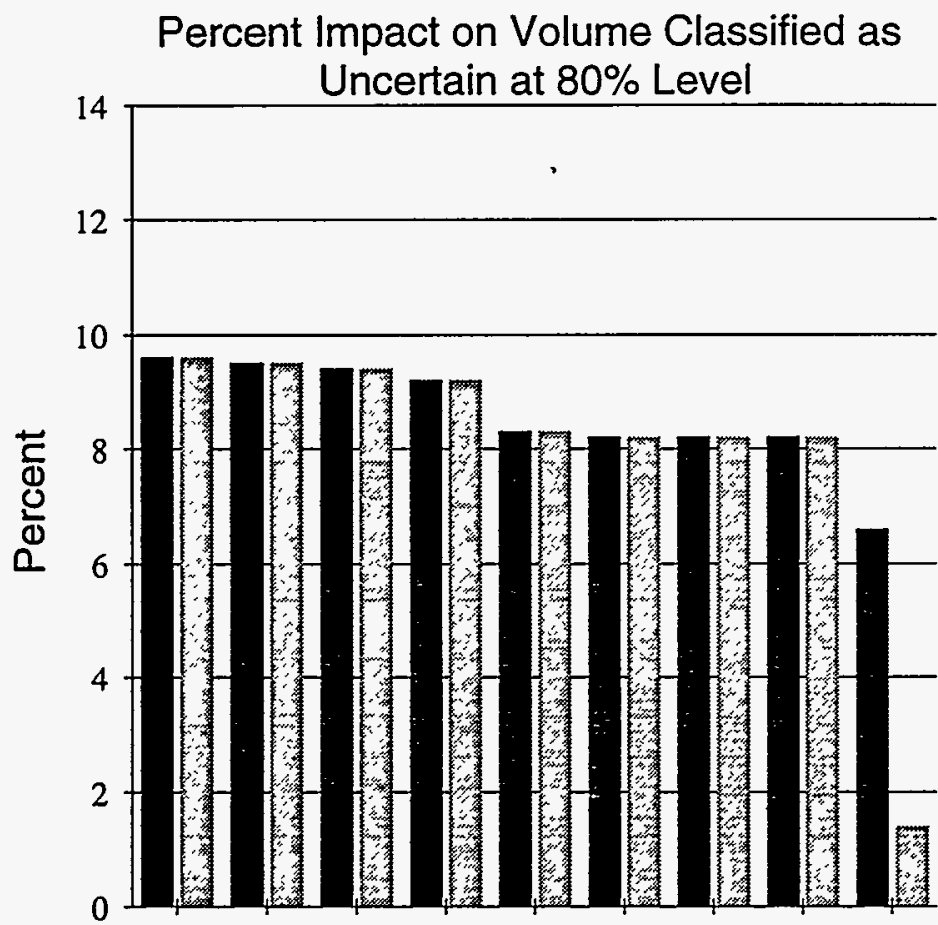

Expected Impact
Observed Impact

PB-1 PB-2 PB-3 PB-4 PB-5 PB-6 PB-7 PB-8 PB-9

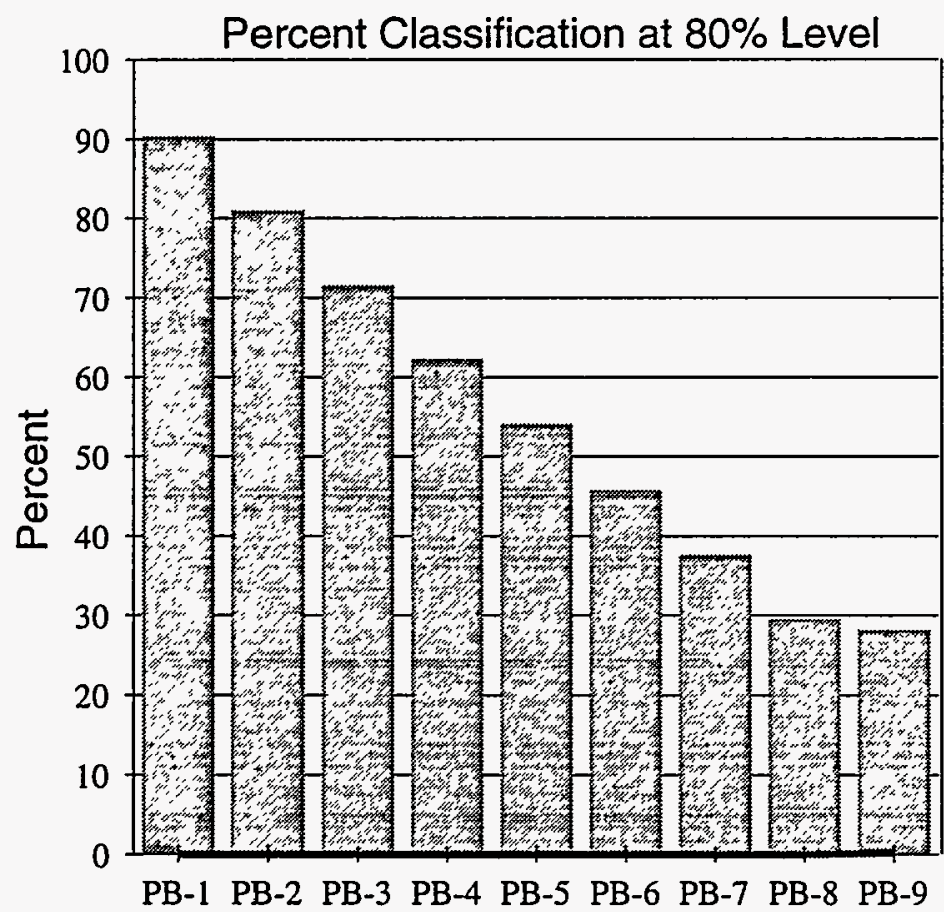

Contaminated

Uncertain

- Best Contam Guess

FIGURE 16 Sampling Program Expected Impact, Actual Impact, and Soil Classification for Altered Initial Location Assumptions 

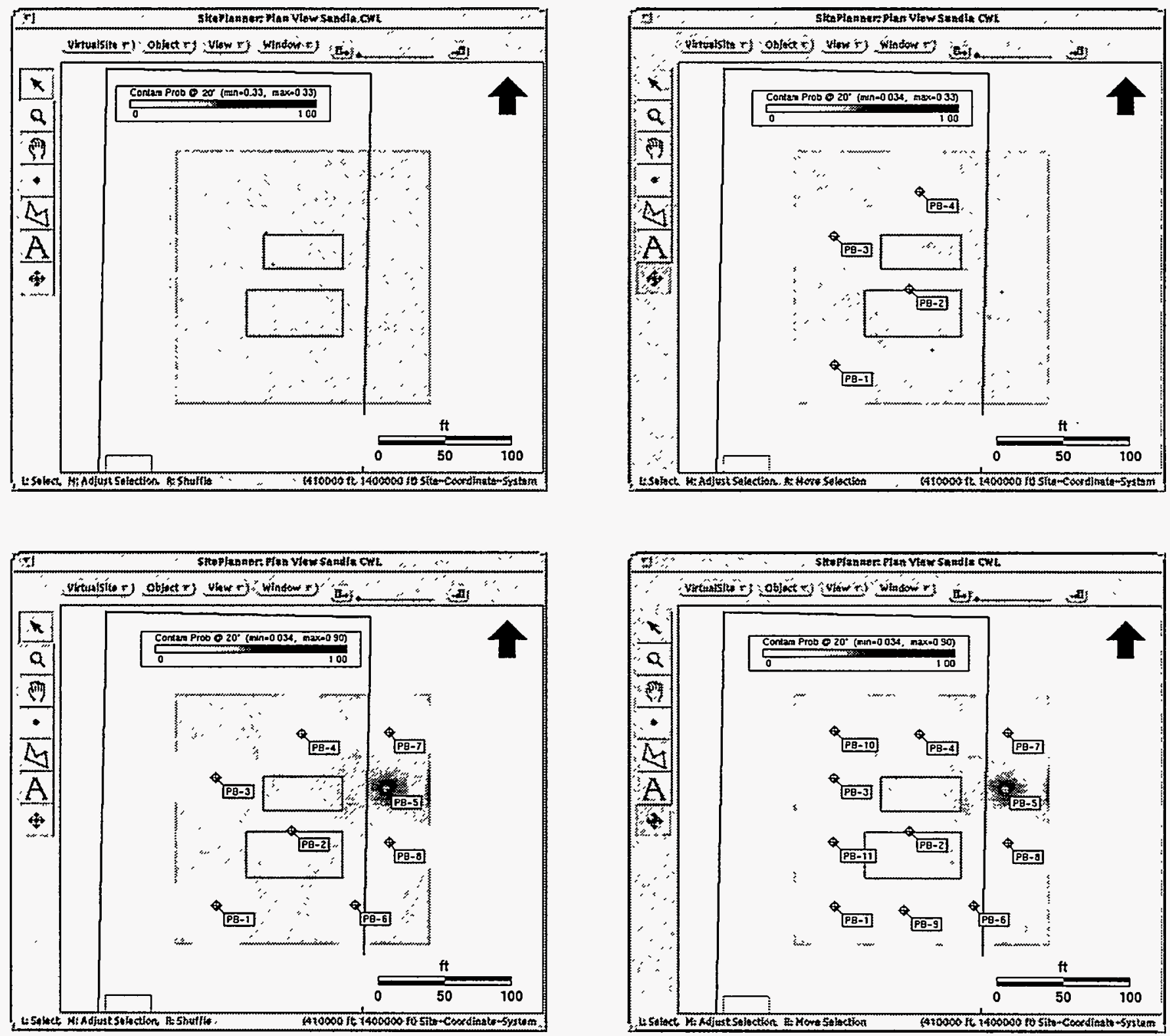

FIGURE 17 Sampling Program Progress with Altered Program Objectives, and Lateral Contamination Extent at a Depth of 20 Feet 


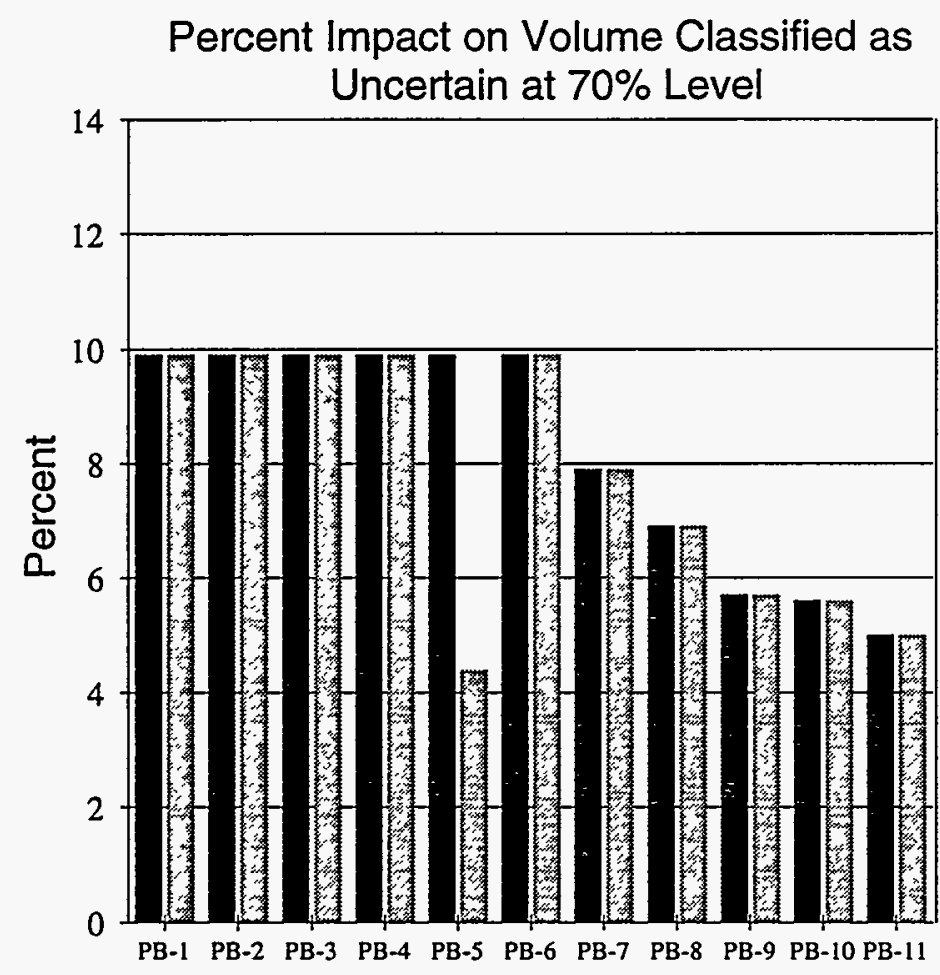

Expected Impact Observed Impact

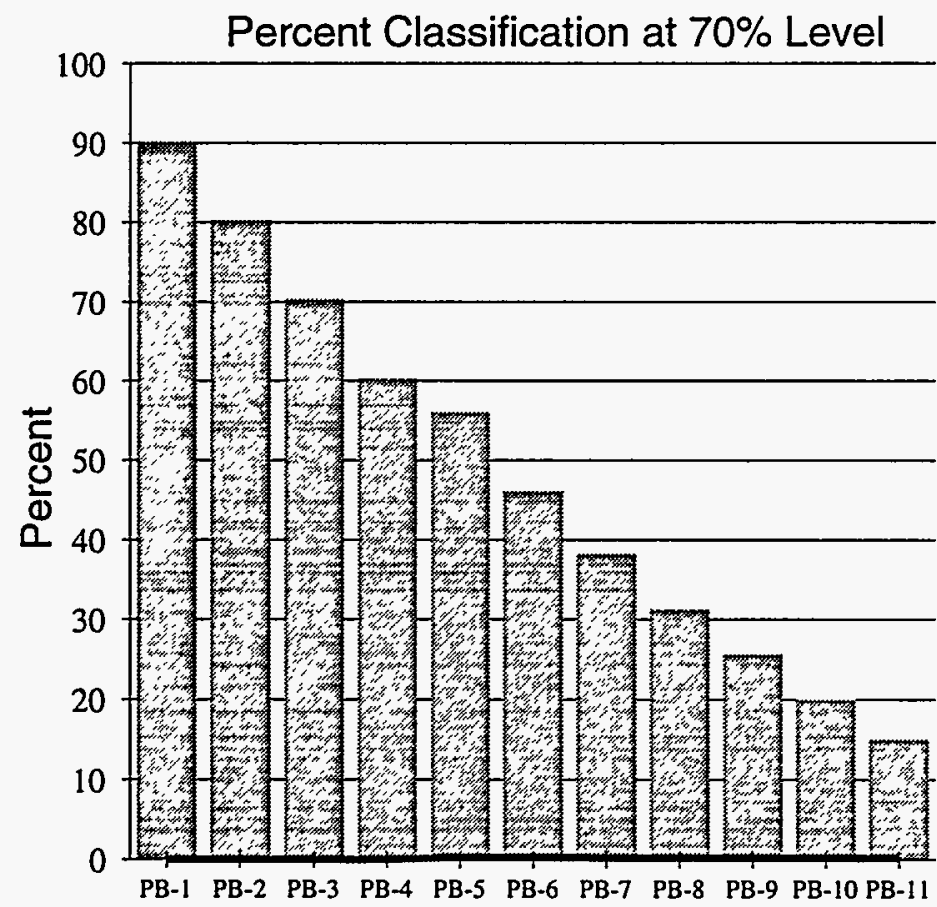

Contaminated

Uncertain Best Contam Guess

FIGURE 18 Sampling Program Expected Impact, Actual Impact, and Soil Classification for Altered Program Objectives 


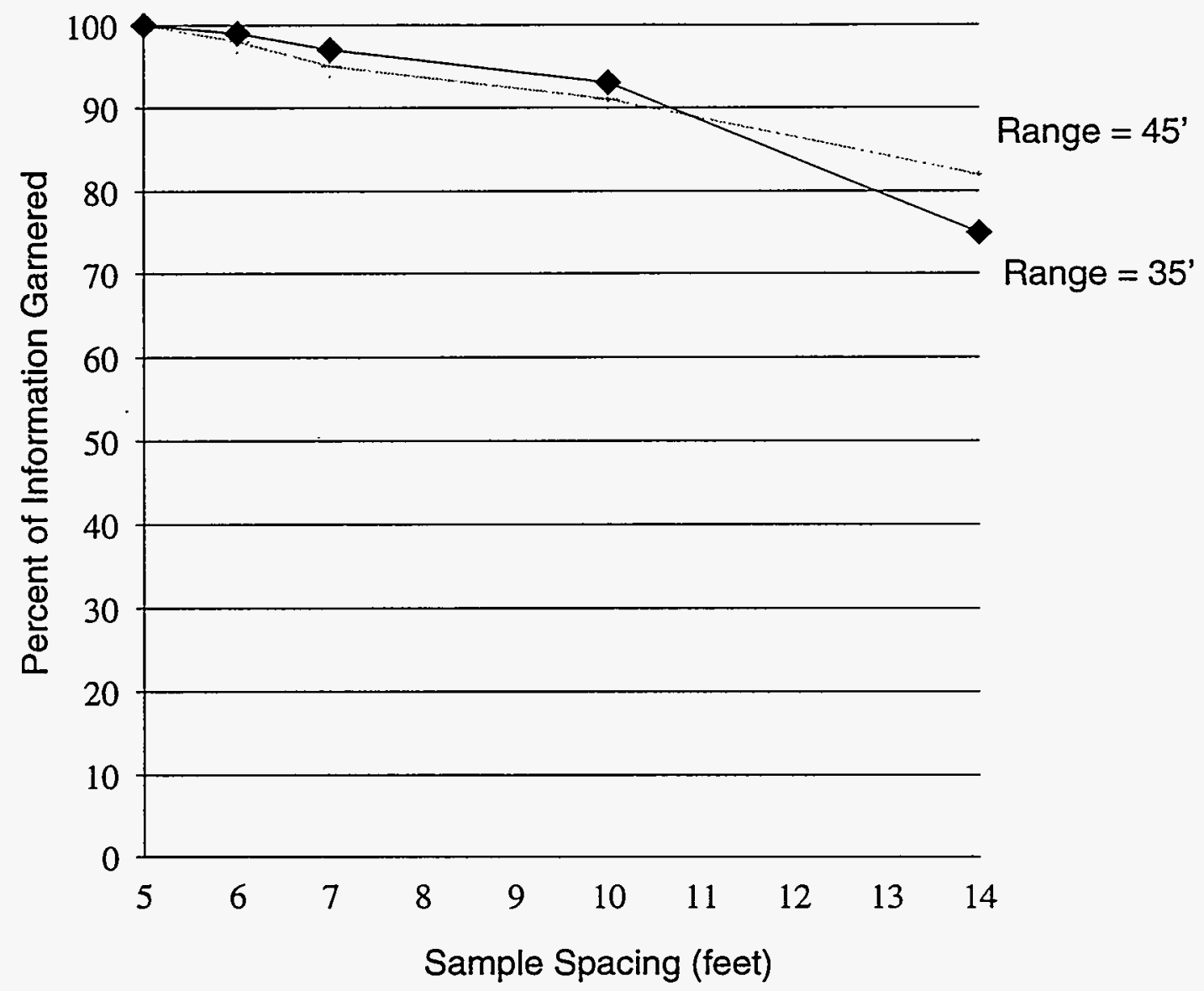

FIGURE 19 Information Gained versus Sample Spacing for the Base Adaptive Sampling Program Case and for the Case with Extended Spatial Autocorrelation Range 

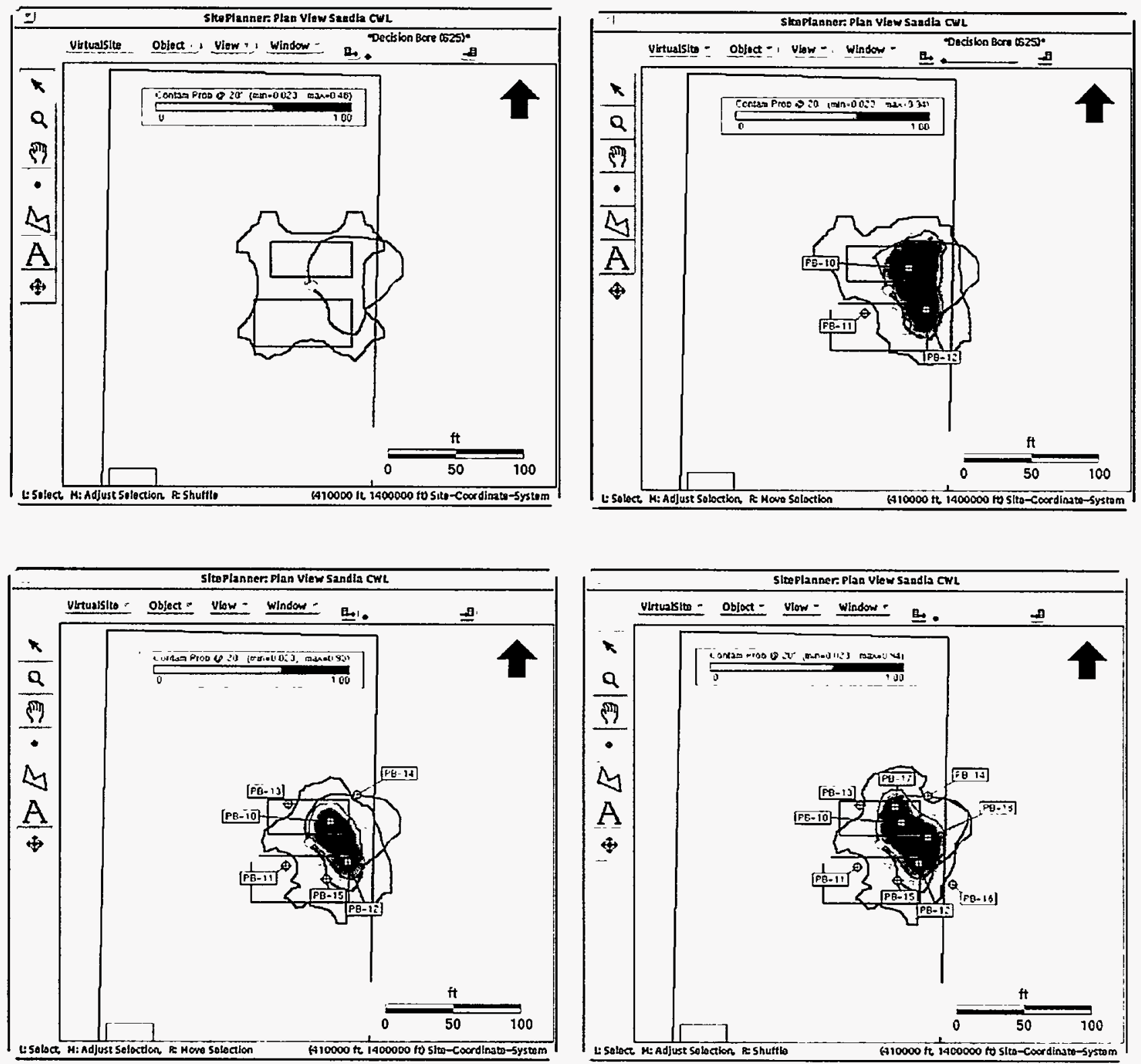

FIGURE 20 Sampling Program Progress for Contaminant Delineation and Lateral Contamination Extent at a Depth of 20 Feet 
Percent Impact on Volume Classified as Uncertain at $80 \%$ Level

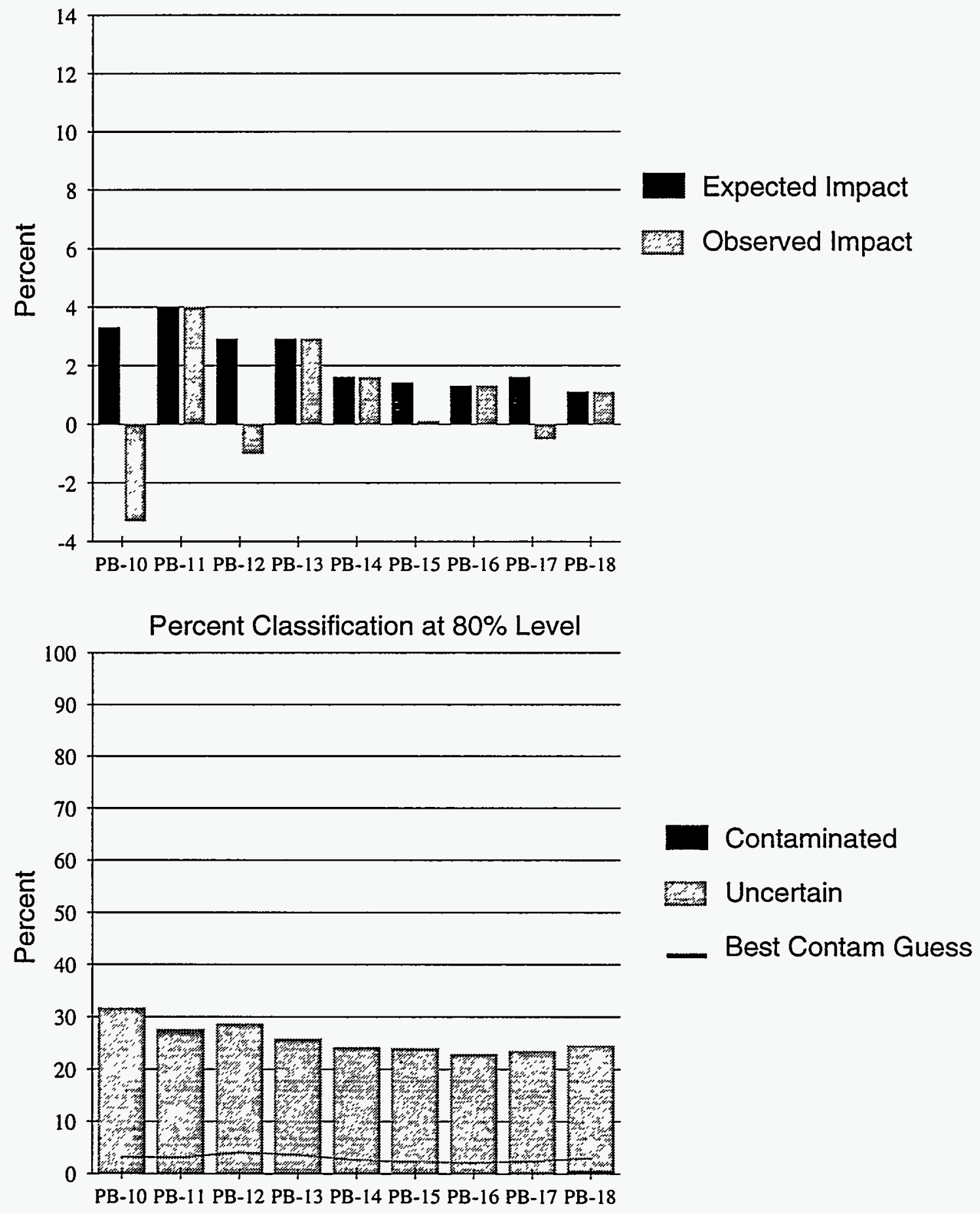

FIGURE 21 Sampling Program Expected Impact, Actual Impact, and Soil Classification for Extended Program 


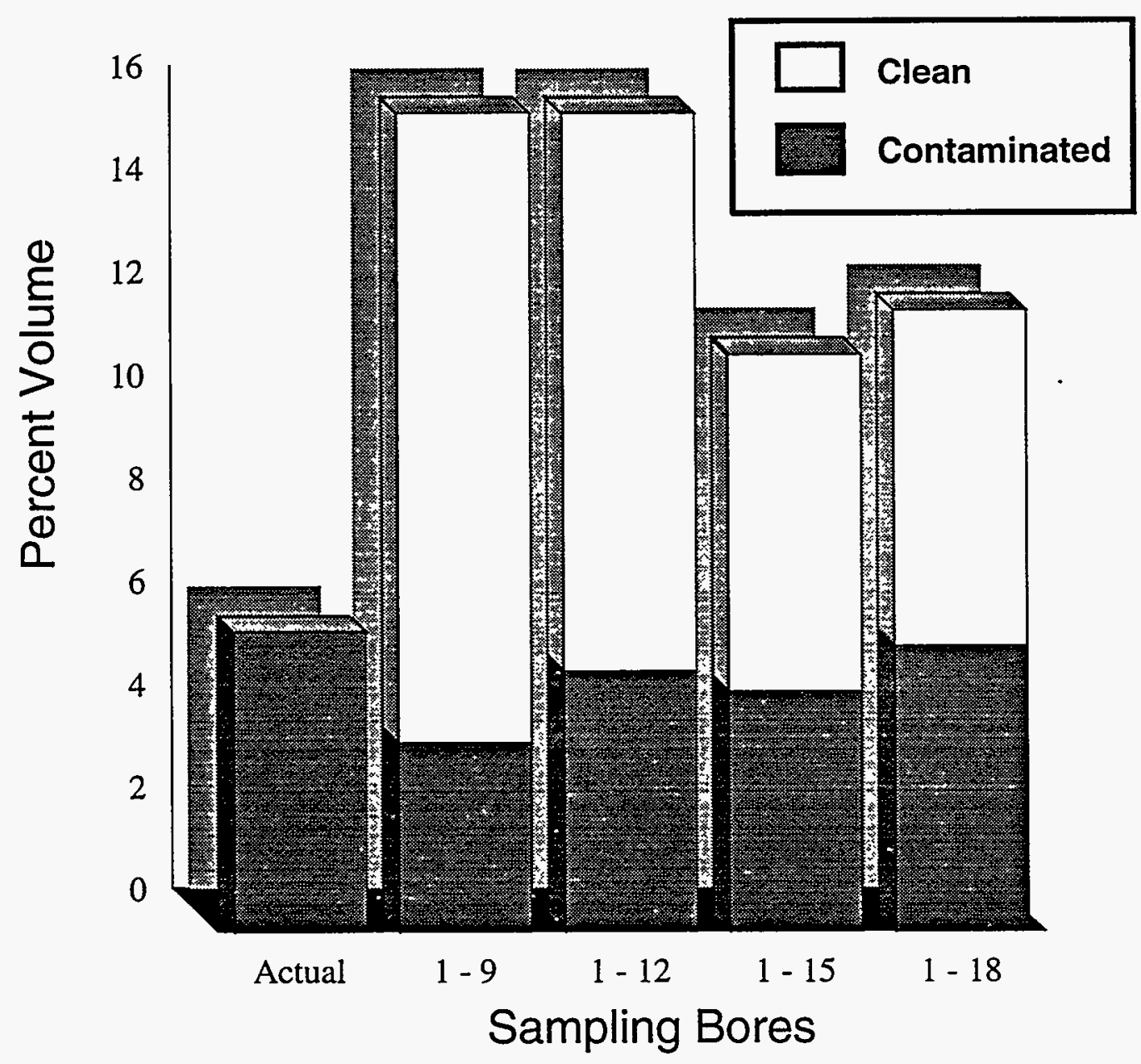

FIGURE 22 Percent Soil Volume Classified for Remediation at $80 \%$ Certainty Level for Various Stages in the Sampling Program 